\title{
The Role of Parasitism in Adaptive Radiations-When Might Parasites Promote and When Might They Constrain Ecological Speciation?
}

\author{
Anssi Karvonen $^{1}$ and Ole Seehausen ${ }^{2,3}$ \\ ${ }^{1}$ Department of Biological and Environmental Science, Centre of Excellence in Evolutionary Research, \\ University of Jyväskylä, P.O. Box 35, 40014, Finland \\ ${ }^{2}$ Department of Fish Ecology and Evolution, Eawag: Centre of Ecology, Evolution and Biogeochemistry, Seestrasse 79, \\ 6047 Kastanienbaum, Switzerland \\ ${ }^{3}$ Division of Aquatic Ecology \& Macroevolution, Institute of Ecology and Evolution, University of Bern, Baltzerstrasse 6, \\ 3012 Bern, Switzerland
}

Correspondence should be addressed to Ole Seehausen, ole.seehausen@eawag.ch

Received 16 August 2011; Revised 28 November 2011; Accepted 2 January 2012

Academic Editor: Andrew Hendry

Copyright (C) 2012 A. Karvonen and O. Seehausen. This is an open access article distributed under the Creative Commons Attribution License, which permits unrestricted use, distribution, and reproduction in any medium, provided the original work is properly cited.

\begin{abstract}
Research on speciation and adaptive radiation has flourished during the past decades, yet factors underlying initiation of reproductive isolation often remain unknown. Parasites represent important selective agents and have received renewed attention in speciation research. We review the literature on parasite-mediated divergent selection in context of ecological speciation and present empirical evidence for three nonexclusive mechanisms by which parasites might facilitate speciation: reduced viability or fecundity of immigrants and hybrids, assortative mating as a pleiotropic by-product of host adaptation, and ecologically-based sexual selection. We emphasise the lack of research on speciation continuums, which is why no study has yet made a convincing case for parasite driven divergent evolution to initiate the emergence of reproductive isolation. We also point interest towards selection imposed by single versus multiple parasite species, conceptually linking this to strength and multifariousness of selection. Moreover, we discuss how parasites, by manipulating behaviour or impairing sensory abilities of hosts, may change the form of selection that underlies speciation. We conclude that future studies should consider host populations at variable stages of the speciation process, and explore recurrent patterns of parasitism and resistance that could pinpoint the role of parasites in imposing the divergent selection that initiates ecological speciation.
\end{abstract}

\section{Introduction}

Since the publication of the Darwin's “Origin of species" one and a half centuries ago, processes and mechanisms by which new species arise have fascinated evolutionary biologists. It is increasingly apparent that the rich biodiversity found on our planet has, at least partly, evolved in bursts of adaptive diversification, associated with the quick origin of new species, referred to as adaptive radiation $[1,2]$. The intensive research on speciation of the past 20+ years, initiated perhaps by the publication of "Speciation and its consequences" [3], has produced much support for the hypothesis of speciation through divergent natural selection, often referred to as "ecological speciation" [4-8]. Ecological speciation research has now begun to integrate ecological and genomic research towards the identification of genes that are important at the onset of ecological speciation in a few systems [9-13]. However, at the same time, some of the most basic questions, such as what factors initiate and drive the emergence of reproductive isolation between diverging populations, remain unanswered for all but a handful of systems. Traditionally, research on ecological speciation has focused on habitat and trophic specialization and on the role of resource competition, as drivers of divergence and reproductive isolation within and between populations $[14,15]$. Some of the recent empirical evidence 
supports the role of these mechanisms (reviewed in $[6,8]$ ). Moreover, predation has classically been considered as an important potential driver of divergence [16], and this idea has recently been explored in a number of papers (e.g., $[17,18])$.

Parasitism is a predominant biological interaction in the wild $[19,20]$, but it has received relatively little attention in speciation research. Parasites live on the expense of other organisms by taking some or all of the energy they need from their host. Because of this peculiar life style, parasites have significant ecological and evolutionary consequences for hosts and host populations [21-24]. Potentially, infections might also initiate, facilitate, or reinforce speciation by imposing selective pressures that differ in form and strength from those imposed by the abiotic environment. Parasites may also impose a range of interrelated effects on host appearance, behaviour, condition, and, importantly, defence system. Classical papers have identified parasites as important sources of divergent selection $[25,26]$ and there is strong evidence to support their role as mediators of species coexistence $[27,28]$. However, while this has led some authors to make far-reaching statements about the role of parasites in driving host diversification, evidence for speciation driven by parasites is very limited (though evidence may be strong for intraspecific genetic host diversity). The reasons for this lack of evidence are several: most studies to date are correlational and cannot separate cause and effect regarding diversity in parasites and hosts. For example, while some studies conclude that parasite diversity is a result of host diversity (e.g., [29, 30]), others have concluded the opposite even with the same data sets [31]. Coevolution that commonly prevails in host-parasite interactions is predicted to generate diversity at least in some constellations [32], and there is wide-spread empirical support for parasites diverging in response to host speciation ([33-35], [36] for a model). Such speciation may be ecological but is mediated by resource specialization and not by parasites. Yet, in cases of cospeciation, it can be difficult to interpret which one (if any) of the coevolving partners actually triggered the speciation in the other one. Moreover, divergence in parasite infections is commonly associated with divergence in food regimes and habitat [37-39]. This makes it difficult to infer parasite-mediated host divergence when there is coincident multivariate divergent selection between niches. It is also possible, and supported by some data, that parasites may actually prevent host speciation $[40,41]$.

In the present paper, we review and discuss the role that parasites might have in ecological speciation and adaptive radiation of their hosts. We go through the existing literature on the theory of parasite-mediated selection and discuss mechanisms that could lead to reproductive isolation in allopatric, parapatric or sympatric host populations, and the prerequisites for these mechanisms to operate. We then review the empirical literature on parasite-mediated speciation with an emphasis on fishes and birds. Hoping not to miss recent publications, we viewed all papers published in the past two years (May 2009 to July 2011) that were retrieved from Web of Science using the combination of search terms "parasite" and "speciation." We also point out some important tests on the theory of parasite-mediated ecological speciation which are currently lacking. Essentially, these concern the initial stages of the speciation process, that is, at which stage of the speciation continuum do parasite infections become divergent among the host populations, and do they importantly restrict the gene flow between host populations? Also, we contrast the role of diversity of a parasite community with the role of single parasite species in driving parasite-mediated speciation, conceptually linking this to discussion on multifariousness of selection and the strength of selection. Finally, we discuss how different types of infections that, for example, alter host behaviour or visual abilities, could influence the process of speciation, or its reversal. We limit this review to metazoan and microparasite (protozoans, bacteria, and viruses) infections, while acknowledging that reproductive isolation and speciation may occur also in other fascinating parasitic interactions. These include, for example, brood parasitism in birds [42], where the interaction differs from "traditional" host-parasite systems as the parasite is not physically attached to the host, and symbiotic bacteria-host interactions, where mating preference can develop as a side effect of host adaptation to the environment [43]. We also restrict our review of empirical evidence to the zoological literature, but acknowledge that there is a larger body of evidence for speciation in plants driven by coevolution with pathogens and predators (see [33] as a classical starting point). There is also a wealth of recent literature on speciation in microbial systems, such as bacteria-phage interactions (e.g., [44, 45]), which is not considered here. We provide examples mainly from fishes and birds where some of the best case studies of ecological speciation and adaptive radiation exist and significant progress has been made in testing predictions from models of parasite-mediated speciation.

\section{Prerequisites for Parasite-Mediated Divergent Selection}

There are three main prerequisites for parasite-mediated divergent selection to operate in natural host populations. First and the most obvious is that infections should differ within or between the host populations. This can happen in allopatric host populations experiencing differences in diversity or magnitude of infections, but also in sympatric or parapatric populations where heterogeneities in ecological (the extent of exposure) or genetic (susceptibility) predisposition to infection create subgroups or subpopulations that have different infection levels. Overall, heterogeneities in infections within a host species inhabiting different geographical areas represent one of the best known phenomena in host-parasite interactions, and basically lay the foundations for investigating parasite-mediated divergent selection. For example, it is well known that ecological factors such as differences in host population structure or in environmental factors may generate variation in infection among populations of one host species (e.g., [46-48]). Typically, this is seen as a decrease in similarity of parasite species composition with increasing geographical distance among the host populations $[49,50]$ or even among different 
locations within one host population [51]. Overall, such heterogeneities of infections could generate highly variable conditions for parasite-mediated selection.

The second prerequisite for parasite-mediated divergent selection is that differences in infections should remain reasonably constant among the host populations through time, thus maintaining the direction and perhaps also the strength of the divergent selection. For example, infections could be highly predictable with the same species composition and more or less similar infection intensities occurring in hosts every year, or show high levels of stochastic year-toyear variation among the host populations causing parasitemediated selection to fluctuate in strength and direction and making consistent divergent selection unlikely. Similarly, spatial repeatability of infections across replicated host populations can be important when evaluating the role of parasites in speciation. In particular, such repeatability could reveal patterns of parallel ecological speciation, which is discussed in more detail below. Moreover, if host divergence is more likely across populations when certain parasite species are present (or absent), this can support the role of these parasites in host divergence. We come back also to this topic later in this paper.

The third important prerequisite for parasite-mediated divergent selection is that infections impose fitness consequences for the hosts and that these are sufficiently strong to overrule possible conflicting fitness consequences of other factors. This is required for parasites to actually impose net divergent selection between host populations. Such fitness consequences are generally assumed because parasites take the energy they need from the hosts which may result in reduced host condition and reproduction. Testing it, however, requires empirical measurement of fitness in nature or in reciprocal transplants that simulate natural conditions, whereas measurement of infection-related fitness components is insufficient. An important feature of host-parasite interactions is that wild hosts are typically infected with a range of parasite species at the same time. For example, in aquatic systems, individual fish hosts are commonly infected with dozens of parasite species simultaneously (e.g., [46, 47]). This is important in terms of direction and magnitude of selection. Under such circumstances, parasite-mediated divergent selection could be driven by a single parasite species having major impact on host viability or reproduction. Alternatively, selection could represent joint effects of multiple parasite species, each with unique types of effects on the host and possibly opposing effects in terms of divergent selection (e.g., see recent discussion in Eizaguirre and Lenz [52] on selection on MHC polymorphism). Separating such effects in natural host populations is a demanding task, which is discussed more below.

\section{Mechanisms and Empirical Evidence of Parasite-Mediated Host Speciation}

In a review on this subject eight years ago, Summers et al. [53] concluded that theory suggests that parasitehost coevolution might enhance speciation rates in both parasites and hosts, but empirical evidence for it was lacking. Since then, new empirical evidence has been gathered, and some of it supports the hypothesis of parasite-mediated ecological speciation, yet overall the empirical support is still scant. Some of the best data to test the hypothesis come from freshwater fish and from birds. Progress has recently been made in some of these key systems in identifying differences in infections among populations, ecotypes and/or sister species (the first prerequisite for parasite-mediated selection), and connecting these to possible mechanisms initiating, facilitating, or maintaining host population divergence and speciation. Table 1 summarizes some of the best studied examples. Here, we first review the existing literature on divergent parasite faunas in ecotypes of freshwater fishes where much new data have been gathered recently. Second, we bring up examples of studies that have gone further into testing predictions of mechanisms of parasite-mediated speciation and discuss these under the three categories of mechanisms: reduced immigrant and hybrid viability or fecundity, pleiotropy, and ecologically based sexual selection. For this second part of the review, we do not restrict ourselves to fish.

3.1. Divergent Parasite Infections. Despite the wealth of the literature on heterogeneities in parasite infections across host species and populations, surprisingly few empirical studies have investigated differences in parasite species composition in sympatric and parapatric host ecotypes or sister species in the context of parasite-mediated divergent selection and speciation. In fishes, such systems include salmonid and three-spine stickleback populations in the northern hemisphere, as well as cichlid fishes in East African great lakes (Table 1). For example, parapatric lake and river populations of sticklebacks in northern Germany differ in parasite species composition so that lake populations harbour a significantly higher diversity of infections [54-56]. Differences in parasitism have also been reported between marine and freshwater ecotypes of stickleback [57], as well as between sympatric stickleback species specializing on benthic and limnetic environments in lakes of Western Canada [58]. In all of these systems, divergent patterns of infection are most likely explained by differences in parasite transmission between different environments or by adaptation of the immune defence to these habitats [54, 56]. Other systems in the northern hemisphere also include whitefish and Arctic charr in lakes in Norway, where ecotypes and species inhabiting pelagic versus benthic habitats, and profundal versus benthic/pelagic habitats, respectively, show significant differences in parasite infections $[59,60]$. Similar differences in infections have also been reported from four ecotypes of Arctic charr in a large lake in Iceland (Figure 1); ecotypes inhabiting littoral areas are more heavily infected with parasites transmitted through snails while the pelagic ecotypes harbour higher numbers of cestode infections transmitted trophically through copepods [61]. Moreover, we have recently observed differences in parasitism between whitefish populations and species reproducing at different depths in Swiss prealpine lakes [62]. 
Divergent parasite infections have also been described from cichlid fish in the lakes of East Africa, especially Lake Malawi and Lake Victoria. These systems are particular as they harbour a tremendous diversity of hundreds of cichlid fish species each that have emerged in the lakes in a few ten thousand to one or two million years [63-65], representing spectacular examples both of biodiversity and adaptive radiation, and of the high rates with which these can emerge. Recently, Maan et al. [66] described divergent parasite species composition in the closely related sister species Pundamilia pundamilia and P. nyererei of Lake Victoria. These differences were caused mainly by larval nematodes in the internal organs and ectoparasitic copepods associated with feeding more benthically in shallower water or more limnetically and slightly deeper. Similarly, heterogeneous infections have been reported in Lake Malawi, where the closely related species Pseudotropheus fainzilberi and P. emmiltos show divergent parasite species composition particularly in terms of certain ectoparasitic and endoparasitic infections [67].

Overall, such differences in infections fulfil the first prerequisite of parasite-mediated divergent selection and support the idea of a possible role of parasites in ecological speciation. However, it is still difficult to evaluate the generality of these findings. This is first because the number of empirical studies describing divergent parasitism among host ecotypes is still quite limited and examples only come from few relatively well-known systems. Second, it is possible that there is an ascertainment bias in the literature so that studies reporting nonsignificant differences in infections tend to not get published. This would be particularly likely with hosts in early stages of the speciation continuum if infections are not yet significantly divergent. However, we point to the necessity of such data in detail below. Overall, differences in parasite infections between diverging hosts alone do not reveal mechanisms underlying speciation, which we will discuss next.

3.2. Mechanisms of Parasite-Mediated Host Speciation. Speciation is a complex process, typically characterized by simultaneous operation of several factors and a cascade of events from initiation to completion. One of the most challenging problems in speciation research is to determine the relative importance to initiating, stabilizing, and completing the process of the many factors that typically vary between populations, incipient and sister species. Given that speciation is most readily defined as the evolutionary emergence of intrinsic reproductive barriers between populations, the most central question in speciation research is which factors drive its emergence, and what is the sequence in which they typically play? In this paper we are concerned with the mechanisms by which parasites could initiate the emergence of reproductive isolation, or facilitate or reinforce it after it had been initiated by other (ecological) factors. This also leads to a key question: at which stage of the speciation process do infections become divergent and begin to reduce gene flow between the host populations? In other words, do host divergence and the initiation of reproductive isolation follow divergence in parasite infections, or vice versa?
We consider three nonexclusive categories of mechanisms (Figure 2).

(1) Direct natural selection: reproductive isolation due to parasite-mediated reduction of immigrant and hybrid viability or fecundity [68].

(2) Pleiotropy: direct natural selection operates on the genes of the immune system, and the latter pleiotropically affect mate choice [69].

(3) Ecologically based sexual selection: reproductive isolation due to parasite-mediated divergent sexual selection [8].

The first two categories of mechanisms could be considered byproduct speciation mechanisms, although the first one in particular may require reinforcement selection for completion of speciation. The third mechanism could be considered reinforcement-like speciation [8].

3.2.1. Tests of Parasite-Mediated Viability or Fecundity Loss in Immigrants and Hybrids. In theory, adaptation to habitatspecific parasite challenges in ecotypes experiencing divergent parasite infections could facilitate reproductive isolation between the ecotypes through parasite-mediated selection against immigrants that acquire higher infection load outside their habitat, or hybrids that show nonoptimal resistance against the parasites and higher infection in either habitat (Figure 2). Selection against immigrants was recently investigated in marine and freshwater sticklebacks in Scotland and in Canada [70]. In these systems, anadromous marine fish, ancestral populations to the freshwater ecotypes, regularly migrate to freshwater to breed, but are still reproductively isolated from the resident, sympatric freshwater ecotypes. Using transplant experiments of lab-raised fish to simulate dispersal and antihelminthic treatment, MacColl and Chapman [70] demonstrated that ancestral-type marine sticklebacks contract higher burdens of novel parasites when introduced to freshwater, than in saltwater and suffer a growth cost as a direct result. Susceptibility to parasites and their detrimental effect in freshwater was less in derived, freshwater fish from evolutionarily young populations, possibly as a result of selection for resistance. MacColl and Chapman [70] concluded that differences in infections could impose selection against migrants from the sea into freshwater populations, but they did not test for selection against migrants in the opposite direction. Similar evidence comes from mountain white-crowned sparrows (Zonotrichia leucophrys oriantha), a passerine bird where immigrant males were more heavily infected with bloodborne Haemoproteus parasites and had lower mating success [71]. The authors suggested that immigrant birds may be immunologically disadvantaged, possibly due to a lack of previous experience with the local parasite fauna, resulting in low mating success.

A related mechanism by which direct natural selection could act in generating reproductive isolation is reduced fitness in hybrids, that is, offspring of two divergently adapted individuals from environments or habitats that differ in parasite infections suffer reduced viability or fecundity, for example, because their intermediate resistance 

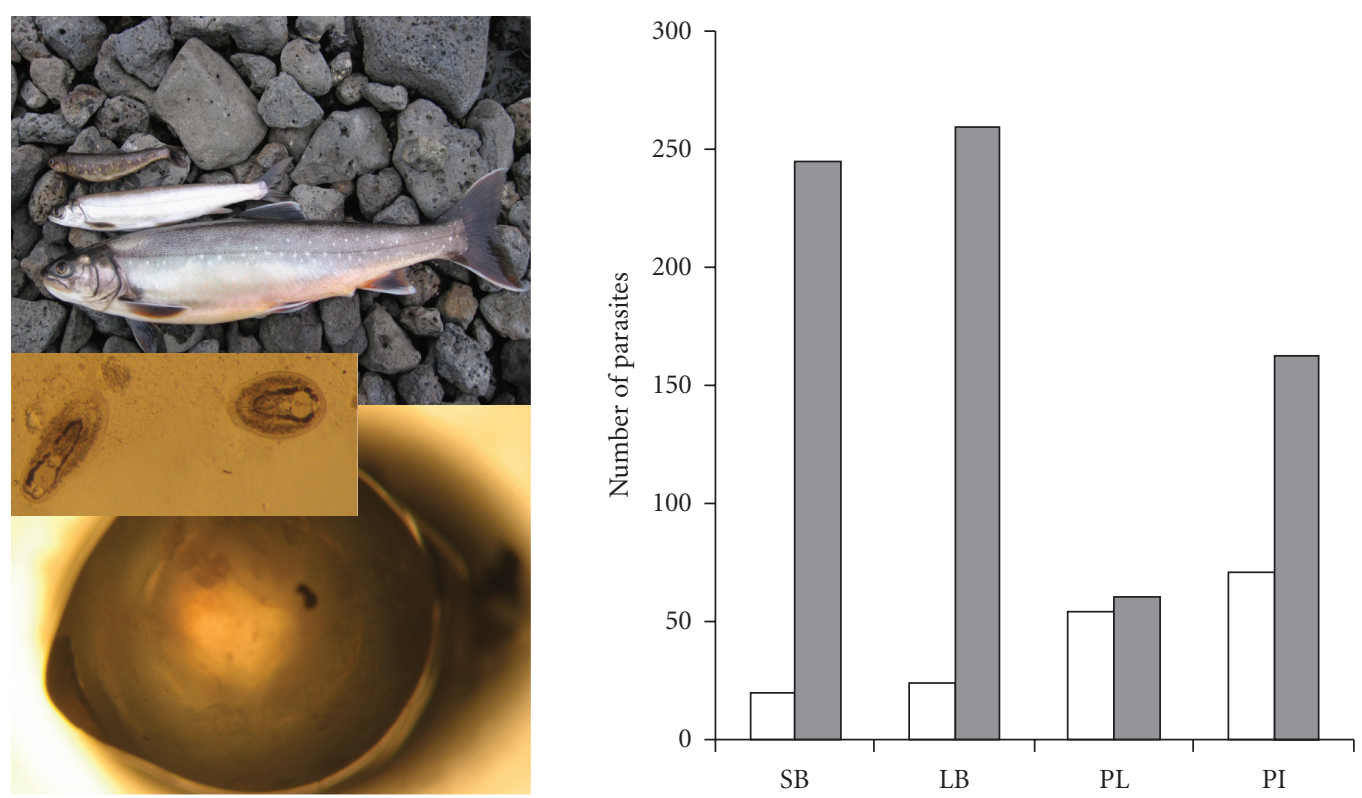

FIGURE 1: Top left: three of the four ecotypes and species of Arctic charr (Salvelinus alpinus species complex) found in Thingvallavatn, Iceland (top left). S. thingvallensis, a small benthic ecotype (uppermost) lives mainly in lava crevices, the pelagic ecotype, one morph of $S$. murta (middle) feeds mainly on plankton in open water, and the large piscivore ecotype, another morph of $S$. murta (lowermost) preys upon smaller fishes. Bottom left: Diplostomum metacercariae in an eye lens of fish (all photos Anssi Karvonen). These widespread and abundant parasites cause cataracts and have significant fitness consequences for the fish. Species of the same genus are also found in the vitreous humour of the fish eye, like in the Icelandic ecotypes of charr. Right: average total sum of cestodes (white bars) and trematodes (grey bars) in the four ecotypes of arctic charr in Thingvallavatn (SB: small benthic S. thingvallensis, LB: large benthic S. sp., PL: planktivorous S. murta, PI: piscivorous $S$. murta). The result illustrates the extent of variation in parasite infections between the sympatric and parapatric ecotypes and interactions between different parasite taxa. Figure produced with permission of John Wiley \& Sons Inc. from data in Frandsen et al. $[61]$.

profiles do not match with either of the environments. There is a wealth of empirical literature on parasitism in animal species hybrids, and a small number of studies report higher infection rates of hybrid individuals, reviewed by Fritz et al. [72] and Moulia [73]. However, most of these studies deal with only distantly related species and interpretation in the context of speciation is problematic. In the context of the present paper, we are interested in examples involving ecotypes, sibling species, or young sister species. We go through recent examples from sticklebacks, mountain white-crowned sparrows and other birds, all of which actually speak against the hypothesis of parasitedriven hybrid inviability and infecundity. Rauch et al. [55] studied hybrids between stickleback from lake populations harbouring high parasite infections and river populations with fewer infections in Northern Germany. Hybrids with intermediate defence profiles in terms of MHC did not suffer higher parasite infections in reciprocal infection trials in either lake or river environments. Similar evidence against the hypothesis of parasite-mediated selection against hybrids has also been presented from collared and pied flycatchers, where individuals living in the hybrid zone of these two sister species showed intermediate prevalence of Haemoproteus blood parasites, as well as intermediate immune responses to infection [74] (Figure 3).

Even stronger evidence against the hypothesis of parasitemediated selection against hybrids comes from work on the mountain white-crowned sparrows. Studying an outbred population for which it was known that parasites reduce fitness, MacDougall-Shackleton et al. [75] found that haematozoan parasite load was significantly negatively correlated with two complementary measures of microsatellite variability. The authors suggested that heterozygote advantage in terms of parasite load may counteract the high parasitism of immigrants (see above), who are likely to produce the most heterozygous offspring (Figure 3). A similar situation has also been reported in a population of song sparrows (Melospiza melodia), a species in which females often display strong preferences for local male song, and that is thought to undergo speciation in parts of its range [76]. Here too immigrants were less likely than residents to breed, but the outbred offspring of these immigrants had higher survivorship [77]. Perhaps the best evidence for parasite-induced loss of hybrid viability comes from studies on hybrid zones between eastern and western house mice $[72,73]$. This is considered as classical tension zone where allopatric lineages with well-divergent genomes meet and hybridize such that some hybrid genotypes suffer intrinsic incompatibilities. House mice F1 hybrids enjoy reduced parasite susceptibility but hybrid breakdown is apparent in higher generation hybrids.

Overall, it is difficult to draw general conclusions on the role of parasite-induced hybrid inviability or infecundity in speciation processes as evidence for parasite-mediated 


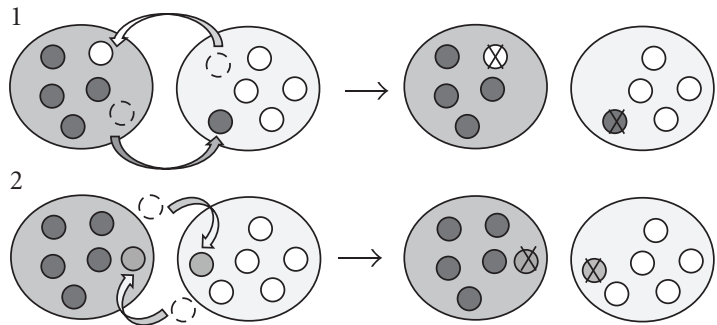

(a)

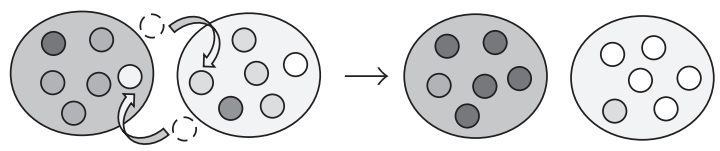

(b)

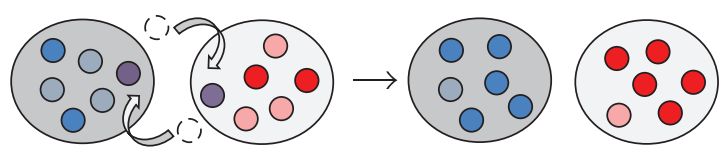

(c)

FIGURE 2: Schematic presentation of models of parasite-mediated speciation. (a) Reproductive isolation due to reduced viability or fecundity of immigrants and hybrids. (1) Immigrants from host populations (a) (dark grey) and (b) (light grey) suffer higher infection levels in the habitat of the other population resulting in reduced survival or fecundity. (2) Hybrids (middle grey) between divergently adapted parent populations (a) and (b) have higher infection levels and reduced survival or fecundity in either of the parental habitats as their intermediate defence profiles cannot match with the parasite pressure of the parental habitats. (b) Reproductive isolation due to pleiotropic effects of MHC on mate choice. Divergence of parasite infections between host populations (indicated by darker and lighter grey background) with initially similar MHC profiles leads to divergent adaptation in MHC profiles to the particular infection conditions (dark grey and light grey). Reproductive isolation between the populations increases in the course of the process through the pleiotropic effects of MHC on mate choice. (c) Ecologically based sexual selection. Two host populations that differ in parasite infections because of habitat or diet, diverge in their use of mating cues because different cues better signal heritable resistance to the different infections (here red and blue). Initially they are weakly reproductively isolated with frequent occurrence of hybrid individuals (purple). Sexual selection for individuals that better resist parasites in a given environment (bright blue and red) over more heavily infected individuals (pale blue and red) facilitates divergent adaptation and results in reproductive isolation between the populations.

selection against hybrids in animal systems is mainly restricted to hybrids between old and genetically very distinct host species [78]. Such data speak little to the role of parasites in speciation just like studies on resource partitioning between old coexisting species do not inform us about the possible role of resource competition in speciation. More controlled experimental studies are needed to tackle effects of parasitism in recently diverged host species in the natural ecological context. Hybrid zones and sympatric hybridising ecotypes would be good places to do such studies.
It is important to note that coevolution in host-parasite interactions may either facilitate hybridisation and gene flow or isolation and speciation, depending on the dynamics of coevolution (reviewed in [53]). For example, locally adapted parasites should have higher success in their resident hosts, providing an advantage to immigrants and hybrids in the hosts, whose genetic profile cannot be matched by the locally adapted parasites (i.e., the enemy release hypothesis in invasion biology). On the other hand, if local hosts are well adapted to their local parasites, and parasites are consequentially not locally adapted, resident hosts should have equal or higher resistance than immigrants and hybrids. In theory, the situation where parasites are ahead of their hosts, should favour speciation between parasite populations but constrain speciation between host populations, whereas the reverse should facilitate speciation between host populations [53]. Few empirical studies of parasite-mediated speciation have explicitly looked at this.

We also point out that the above coevolutionary scenarios between parasites and hosts could commence not only at the level of different parasite species compositions, but also at parasite genotype compositions. Under such circumstances, different coevolutionary dynamics driving divergent parasite-mediated selection between different environments could take place with seemingly identical parasite species assemblies that are "cryptically divergent" showing different genotype composition between the environments. Conceptually, this can be seen as an extension to the hypothesis on divergent selection between contrasting environments.

Moreover, it is important to note that host-parasite interactions commonly show high levels of genetic polymorphism that could fuel speciation potential in parasites and/or hosts. In general, such variation could be maintained by different combinations of genotype by environment interactions $(G \times G, G \times E$ or $G \times G \times E)[79,80]$, for example, as a consequence of parasite-parasite interactions within a coinfecting parasite community [81], or because of effects of environment on host susceptibility [82]. However, genetic polymorphism does not necessarily lead to emergence of new species if factors mediating divergent selection between host populations are absent.

3.2.2. Tests of Pleiotropy: $M H C$ and Mate Choice. Reproductive isolation can also emerge as a byproduct of parasitemediated divergent evolution at the genes of the immune system that pleiotropically affect mate choice (Figure 2). This includes the highly polymorphic family of genes in the major histocompatibility complex (MHC) that encode antigen-presenting molecules and have an important role in identification of non-self-particles and activation of adaptive immunity. They are also often involved in mate choice [69], thus having a pleiotropic role in parasite resistance and reproductive behaviour. The role of MHC in immune defence and mate choice has recently been reviewed by Eizaguirre and Lenz [52]. In theory, MHC-mediated mate choice may lead to assortative mating in host populations, albeit under restricted conditions [83]. This has recently received empirical support in some systems [54] (Figure 4). 

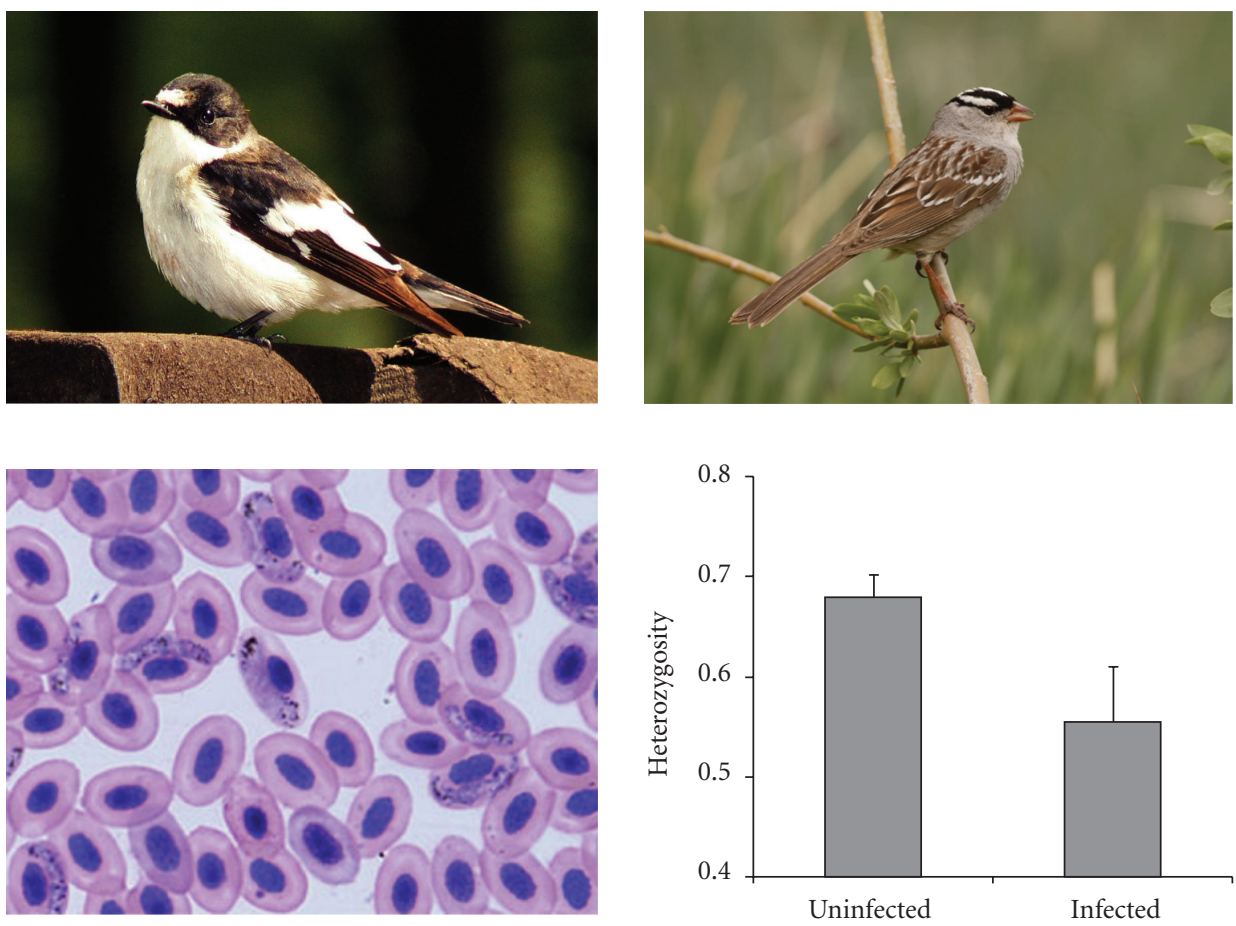

Figure 3: Top left: in the hybrid zone between pied flycatcher (Ficedula hypoleuca) and collared flycatcher (Ficedula albicollis) hybrids showed intermediate prevalence of Haemoproteus blood parasites compared to the parental species, and also intermediate immune responses to infection [74] (photo shows a male hybrid F. hypoleuca $\times$ F. albicollis, courtesy of Miroslav Král). Bottom left: haematozoan blood parasites can be agents of severe selection in birds (photo shows Haemoproteus multipigmentatus infecting red blood cells of endemic Galápagos doves [84], courtesy of Gediminas Valkiunas). Right panels: in the mountain white-crowned sparrows (Zonotrichia leucophrys oriantha) heterozygote advantage in terms of reduced parasite load may counteract elevated parasitism of immigrants, who are likely to produce the most heterozygous offspring [75] (photo courtesy of Bob Steele). Figure reproduced with permission of the Royal Society of London from MacDougall-Shackleton et al. [75].
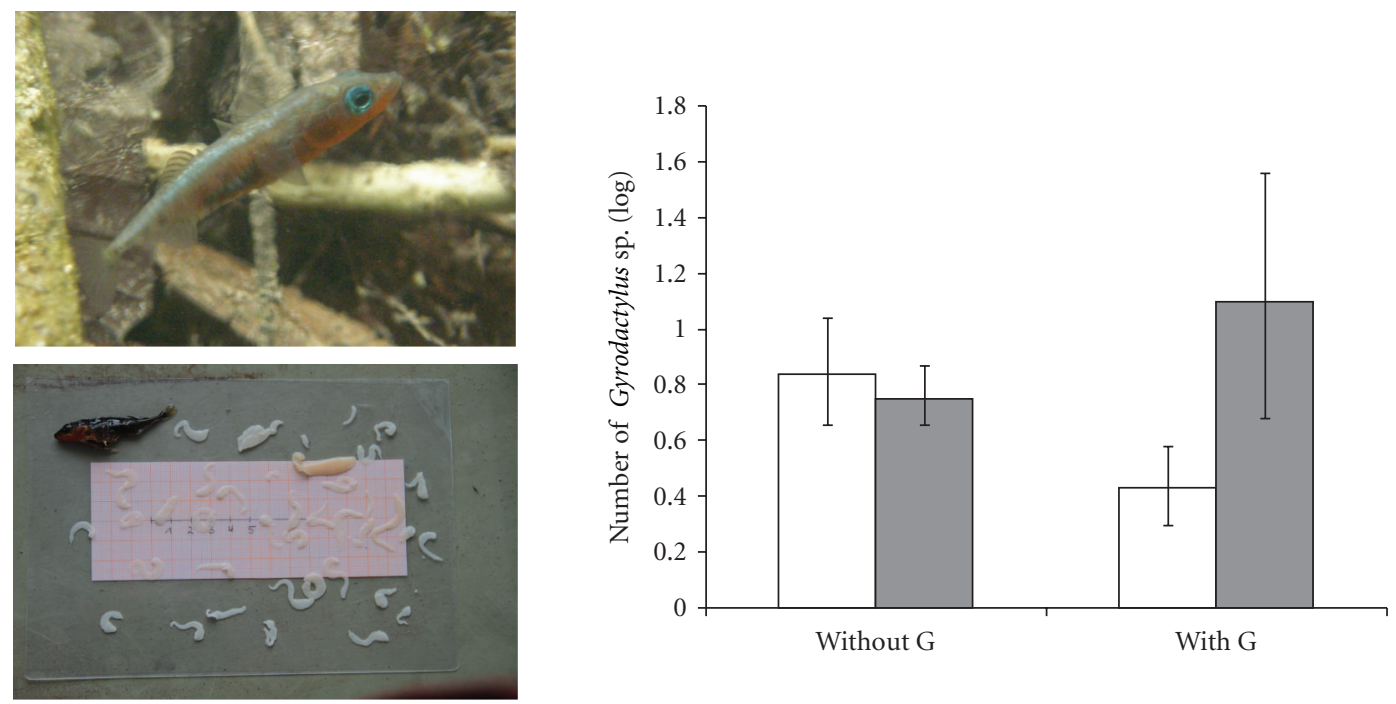

FIGURE 4: Top left: a nuptial male of a lake ecotype of the Three-spined stickleback (Gasterosteus aculeatus species complex, photo Ole Seehausen). Bottom left: a breeding male stickleback and a series of Schistocephalus cestodes that were found in its body cavity (photo courtesy of Kay Lucek). These tapeworms change the behaviour of stickleback and effectively castrate them. Right: mean number of ectoparasitic Gyrodactylus monogenean parasites (log transformed) on Schleswig Holstein lake (grey bars) and river (white bars) sticklebacks, with or without an MHC haplotype G. Occurrence of the haplotype coincides with higher resistance against the parasite in the river ecotype while there is a tendency for the opposite pattern in the lake ecotype. Figure produced with permission from data in Eizaguirre et al. [54]. 


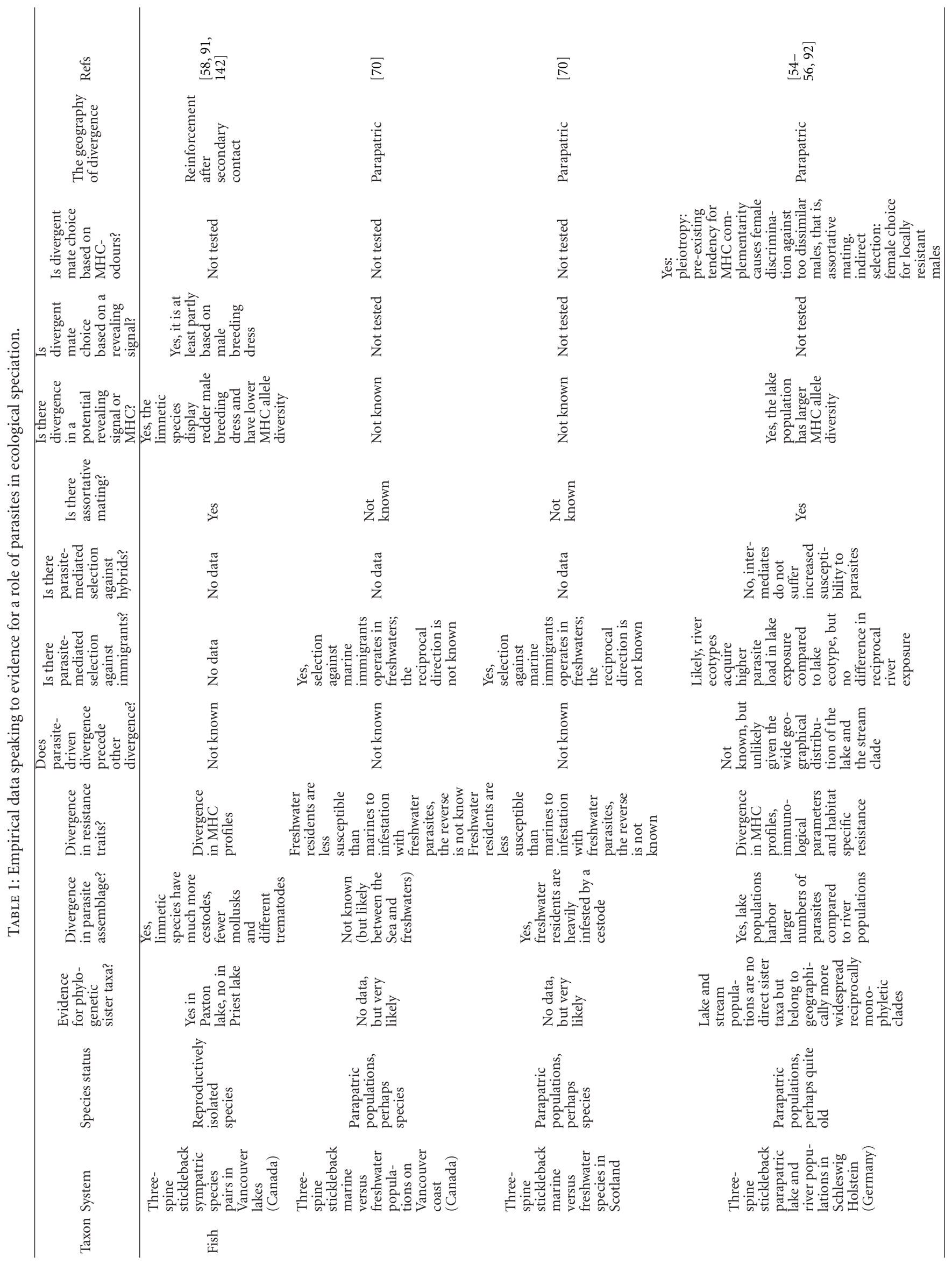




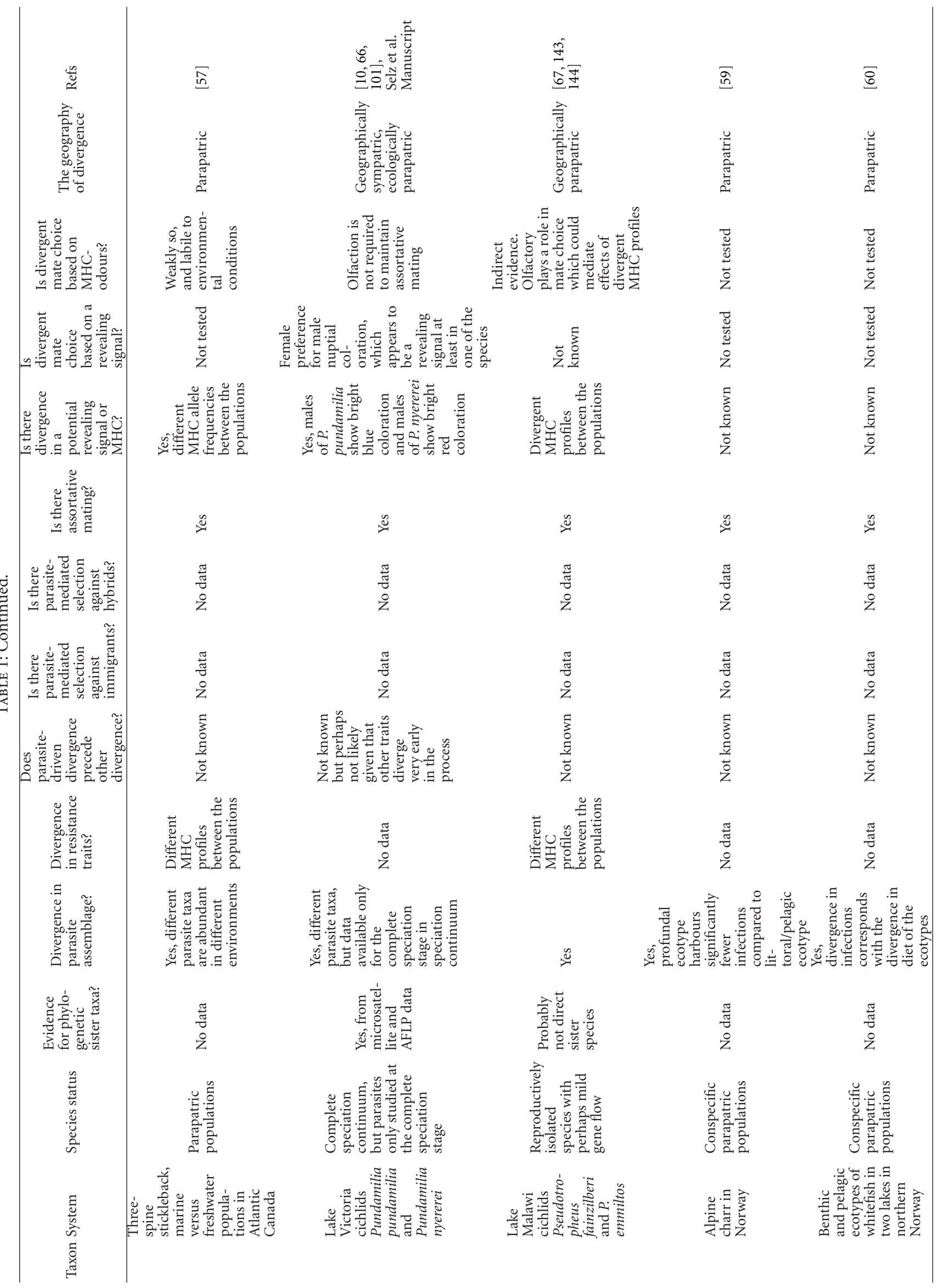




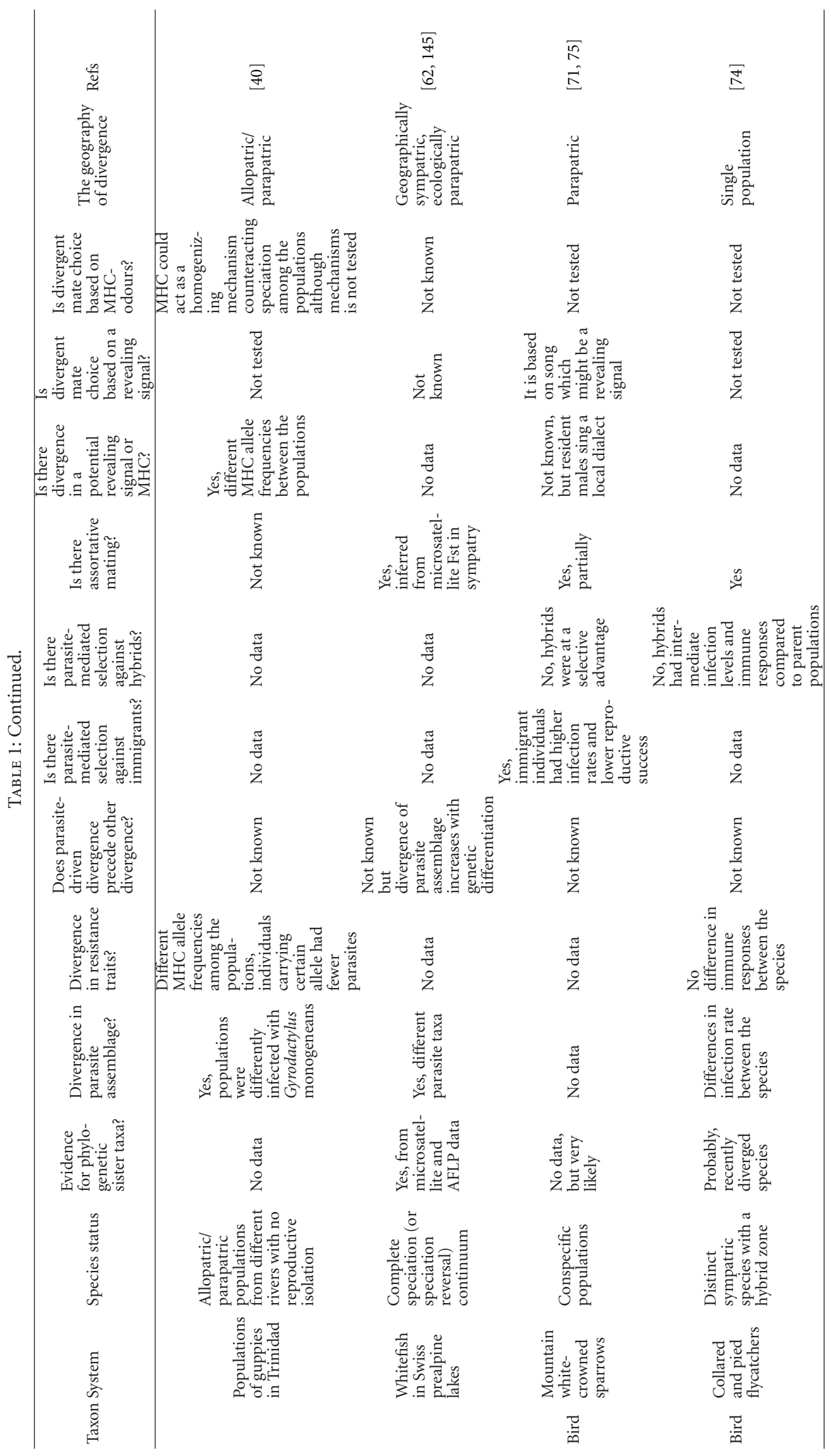



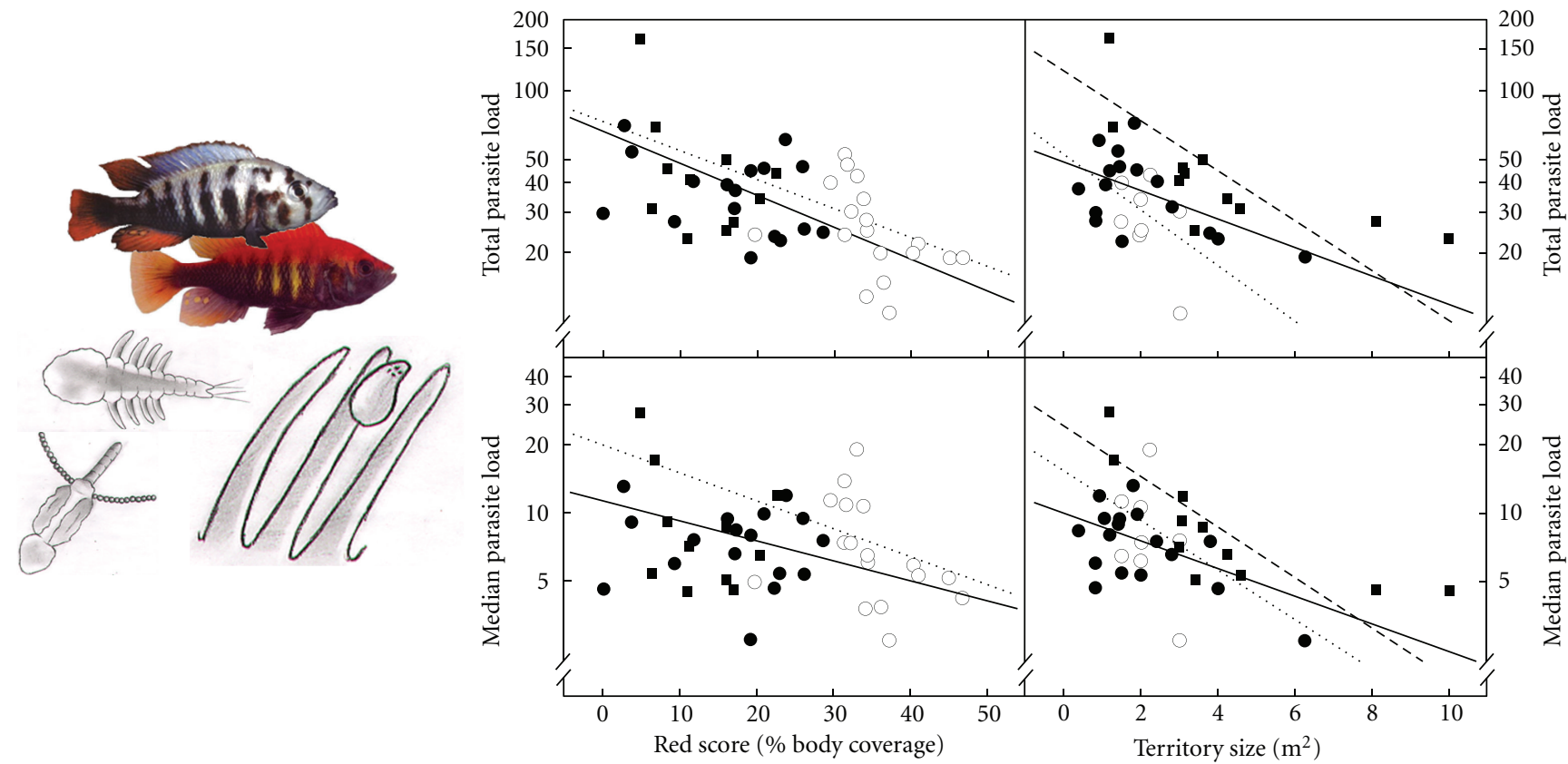

Figure 5: Left: the cichlid fish sister species Pundamilia pundamilia and P. nyererei from Lake Victoria differ in their parasite assemblages, dominated by larval nematodes in the internal organs and ectoparasitic copepods on the gills, respectively (photo of $P$. pundamilia Ole Seehausen, photo of $P$. nyererei courtesy of Martine Maan, drawings courtesy of Jeanette Bieman). Right: males with bright red (shown) or bright blue (not shown) colouration and males with larger territories were found to carry lower parasite infections than males with duller coloration $[66,101]$ and females use male nuptial colouration in intra- and interspecific mate choice [102, 103]. Figure reproduced with permission from Maan et al. [101].

On the one hand, MHC-mediated mate selection is known to often favour outbreeding and associated disassortative mating between and within host populations $[69,85]$. MHC disassortative mating preferences can in principle increase fitness of choosy parents because a disproportionate number of offspring would be high fitness MHC heterozygotes [86]. There is also evidence to suggest that intermediate MHC diversity results in higher fitness for an individual since low diversity allows some parasites to escape immune detection and very high diversity increases the risk of autoimmunity [87]. Under such circumstances, divergent optimality of MHC allele frequencies in contrasting environments that differ in parasite exposure may lead to or facilitate ecological speciation through mate choice for well-adapted MHC profiles in each environment [88, 89]. For example, experimental work with stickleback suggests that female sticklebacks use evolutionarily conserved structural features of MHC peptide ligands to evaluate MHC diversity of their prospective mating partners [88]. It should be noted here that MHC-mediated divergent sexual selection does not require individuals to be infected with the parasite species that has driven the evolutionary divergence in MHC profiles, or with any other parasite. This is in contrast to situations of direct natural selection, for example, when the fitness of immigrants or hybrids is reduced by the actual infection (see above). However, suboptimal or superoptimal MHC profiles of hybrids could still cause higher parasite infection and reduced fitness, adding to reproductive isolation through viability selection as suggested by theoretical models [89].
Much of the empirical work on the interactions between parasitism and diversity of MHC genes has been conducted in contrasting infection environments. Recent progress has been made especially in ecotype and species pairs of threespine sticklebacks in northern Germany and Canada. Lake and river ecotypes of sticklebacks in Germany harbour significantly different parasite communities so that the lake populations are infected with a higher diversity of parasite species [54, 90]. This difference is known to be linked positively with the diversity of MHC genes; more heavily infected lake populations show higher diversity of MHC compared to river populations [54]. Moreover, this is accompanied by variation in resistance between ecotypes where the less-infected river ecotype shows reduced immunocompetence [56]. Such between-habitat variation in the pools of MHC alleles suggests operation of parasitemediated selection, although it does neither imply divergent selection, nor exclude simultaneous action of genetic drift [54]. Somewhat contrasting results on MHC diversity in sticklebacks, however, come from Canadian benthic-limnetic species pairs. In this system, the limnetic ecotype carries higher number of parasites, especially those species likely to impose selection, than the benthic ecotype [58], but still harbour fewer MHC alleles [91].

Outside the stickleback systems, evidence for divergent MHC profiles in ecotypes or young sister species is scarce. One of the few fish examples is the study by Blais et al. on sympatric cichlid species in Lake Malawi [67]. These authors demonstrated high polymorphism in MHC, divergence in 
MHC allele frequencies, and differences in parasite infections between these closely related fish species, supporting the idea of parasite-mediated divergent selection. We expect that more tests will be conducted in ecotypes and young sister species of fish, and other host taxa in the near future. This will be important in establishing the generality of relationships and unravelling the somewhat contradictory results obtained in different systems even with the same host taxon.

The above examples demonstrate heterogeneous MHC profiles between ecotypes and young species. However, very few studies have taken the necessary next step towards testing the MHC-pleiotropy speciation hypothesis by looking into MHC-mediated assortative mating among ecotypes. Again, experimental work here includes that in two stickleback systems. Mate choice trials by Eizaguirre et al. [92] in seminatural enclosures revealed that female sticklebacks from lake populations in northern Germany show preferences for males with an intermediate MHC diversity, and for males carrying an $\mathrm{MHC}$ haplotype that provides protection against a locally common parasite. Subsequently, the same authors extended this approach to lake and river ecotypes and found, using a flow channel design, that females preferred the odour of their sympatric males [54]. They concluded from these studies that parasite-induced divergent selection on MHC diversity and for local adaptation could act as a mechanism of speciation through the pleiotropic role of $\mathrm{MHC}$ in mate choice. However, actual assortative mating between the lake and stream populations remains to be demonstrated. Other authors found in common garden experiments that assortative mating between lake and stream sticklebacks may often not evolve despite divergent selection on ecological traits ([93]; Räsänen et al. this volume [94]). However, it is nevertheless possible that such assortative mating occurs in nature owing to environmental influences.

Assortative mating mediated by MHC has also been studied in saltwater versus freshwater sticklebacks in the St. Lawrence River in Canada [57], where the populations differed significantly in the frequency of MHC alleles and in the communities of helminth parasites. Strong signatures of natural selection on MHC genes were inferred in the freshwater, but not in the marine population. Relationships between parasite load and MHC diversity were indicative of balancing selection, but only within the freshwater population. The latter result is in accordance with other studies on sticklebacks suggesting maximisation of host fitness at intermediate rather than maximal MHC diversity in some environments $[95,96]$. Mating trials found signals of MHCmediated mate choice to be weak and significantly influenced by environmental conditions (salinity; [57]). By allowing full mating contact to the fish, these authors demonstrated differences between the ecotypes in the importance of MHC-mediated mate choice, and very strong environment dependence where mating preferences with regard to MHC were sometimes inversed depending on whether fish were tested in their own or a different salinity environment. The authors concluded that MHC probably plays an important role when individuals evaluate prospective mates, but that MHC-mediated mate choice decisions depend on the environmental conditions and are not necessarily underlying the propensity towards assortative mating [57].

Evidence for a counteracting role of MHC in host speciation, on the other hand, comes from Trinidad guppies [40]. These authors found significantly lower divergence in MHC among guppy populations than expected from divergence at neutral loci and concluded that stabilizing selection on $\mathrm{MHC}$ and its pleiotropic role in mate choice could act as a homogenizing mechanism among the populations [40]. Evidence for stabilizing selection on some and divergent selection on other MHC loci was observed in Alpine trout populations adapting to steep thermal gradients [97]. It is clear from these contrasting results that more examples from different systems are needed to address the generality of parasite-mediated divergent selection on MHC and the role of MHC cues in mate choice among diverging host populations.

3.2.3. Tests of Parasite-Mediated Divergent Sexual Selection. Reproductive isolation in this scenario emerges by sexual selection for direct benefits (i.e., healthy mates) or for heritable fitness (i.e., parasite resistance) as an indirect consequence of adaptation to different parasite challenges (Figure 2). In theory, divergent sexual selection is an effective mechanism of reproductive isolation [98], while parasites are considered mediators of mate choice [99]. Several aspects of parasitism may lead to population divergence under these circumstances (discussed recently in [8]). For example, infections are commonly related to habitat and diet, and they impose selection on signal design, maintain genetic variation and honesty of sexual signalling through the cost they impose on signal production and maintenance, as well as have health consequences for their hosts which may filter down to mate attraction and selection [8]. There are several alternative scenarios for how this may lead to population divergence, but most of the studies so far have been conducted on interactions between parasitism and mating preferences. These are related to the seminal paper by Hamilton and Zuk [99] on the tradeoffs between individuals' ability to resist parasite infections and produce extravagant sexual ornamentation by which sexual selection for healthier mates ensures heritable resistance to offspring. Such selection could also promote speciation if ecological factors that lead to divergent parasite infections result in reproductive isolation through selection for parasite resistance [8].

Empirical evidence comes from freshwater fishes. For example, Skarstein et al. [100] showed that individual Arctic charr (Salvelinus alpinus) within one population had marked differences in habitat and diet, and this correlated also with parasite infection and breeding colouration. Such variation could facilitate niche-specific adaptation in hosts and set the initial stages for speciation through divergent sexual selection. Similarly, in cichlid fish, males with bright red (Pundamilia nyererei) or bright blue ( $P$. pundamilia) colouration were found to carry lower parasite infections than males with duller coloration $[66,101]$. At the same time, females use male nuptial colouration in intra- and interspecific mate choice $[102,103]$ (Figure 5). However, what role 
the divergent parasite infections have in speciation in this system is unclear because parasites have been investigated only in the well-advanced stage of speciation, and because the differences in infections coincide with differentiation in diet, microhabitat, and visual system [66], which supports the idea that parasite-mediated divergent selection is often just one component of multifarious divergent selection between habitats [104]. Overall, it remains to be tested in all of the systems if the preference of females for more resistant males actually results in production of offspring that are more resistant to parasites found in each particular environment [8].

\section{Future Directions: Missing Tests of Parasite-Mediated Divergent Selection}

The empirical examples reviewed above demonstrate recent progress in identifying differences in parasite infections between host populations that occupy contrasting environments and have diverged in phenotypic and genetic traits, and in linking these differences to assortative mating and speciation (Table 1). However, it is also clear that many more empirical tests of the role of parasite-mediated divergent selection in these and other taxa are needed before the generality of some of the more trenchant findings can be assessed. Next we will discuss three categories of tests of parasite-mediated speciation that are currently lacking: parasite-mediated divergent selection along a speciation continuum, the strength of selection versus multifariousness of selection, and measuring the relative rates of adaptation in parasites and in hosts.

4.1. Divergent Selective Pressures along a Continuum of Speciation. We ought to understand at which point of the speciation process parasite assemblages become sufficiently divergent to reduce gene flow between host populations. This is particularly true because divergent infections are usually associated with divergent habitat and/or diet, and hence rarely come isolated from other sources of divergent selection. At present, it remains unknown whether divergence in parasitism could itself initiate the divergence of host populations, or rather follows the divergence of host populations initiated by other ecological factors. In the second case, it is unknown in most cases whether divergence in parasitism is consequential or inconsequential to speciation. Answering these questions requires approaches that capture the entire continuum of speciation (see [104, 105]). This should include replicated populations occupying contrasting habitats, but showing no apparent divergence, and extending to well-differentiated ecotypes and incipient species and eventually all the way to fully isolated sister species [104, 105]. However, all empirical investigations of parasite effects known to us have dealt each with just one stage in the continuum of the speciation process, and in fact often with species that are already divergent in many different traits (Table 1). Nevertheless, there are several potential systems where the speciation continuum approach could be applied. In fishes, the strongest candidate populations would most likely come from African and Central American great lake cichlid fish, and from sticklebacks, charr, and whitefish species in postglacial lakes.

At the same time, studies should consider spatiotemporal variation, or consistency, in parasite-induced selective pressures. Investigating infections over replicated pairs of host populations could reveal if infection patterns are consistently different, for example, among hosts inhabiting two distinct environments. Under such circumstances, infections could drive parallel ecological speciation in different populations [106-108]. In reality, infections almost always differ to some extent among populations in terms of species composition and infection intensities because of heterogeneities in local conditions for parasite transmission. For example, associations between host diet and infection from trophically transmitted parasites could show habitat-specific variation. However, if the "core" of parasites (including one or several species) that underlies selective pressures and host divergence remains more or less the same, parallelism in host divergence among different populations could be observed. Approaches that capture parallelism along a continuum of host speciation could tackle not only the importance of infections in speciation process per se, but the significance of individual parasites species as well (see below).

Similarly, temporal stability of infections on the time scale of host generations would indicate if the strength of selection is stable enough to result in divergence of host populations. So far, the extent of spatiotemporal variation or consistency is unknown in most systems that include a limited number of host populations and/or a narrow temporal window for observations (but see Knudsen et al. [39] for long-term data on Arctic charr in Norway). Attempts to relate such temporal patterns to variation in the progression of speciation have also been few [109]. In general, what is needed are long-term data on spatiotemporal consistency of divergent parasite infections in replicated pairs of host populations that are at different stages of speciation. This is a demanding task, but could help in answering fundamental questions such as whether speciation takes place only in populations where costly infections do not fluctuate randomly. Most importantly, patterns of parasitism must be investigated in an integrated speciation perspective alongside various other ecological and genetic factors some of which would typically interrelate with parasitism. This should include effective combinations of field surveys and experimental approaches to generate real insights into the question of how parasites affect the speciation process in relation to other factors initiating or promoting ecological speciation. For example, divergent parasitism may initiate speciation on its own right, or it may be a necessary force in the transition from early stages of divergent adaptation to assortatively mating species, but it may also latch onto other mechanisms of divergent evolution without being consequential for the process of speciation.

\subsection{Strength versus Multifariousness of Parasite-Mediated} Selection. Divergent selection may act on a single trait, a few traits or many traits at the same time, and in each of these cases selection may have a single or many sources. In 
a recent review, Nosil et al. [5] related this to hypotheses about "stronger selection" when the completion of speciation depends on the strength of selection on a single trait, or "multifarious selection" when completion of speciation is more likely driven by independent selection on several traits [5]. A predominant feature of natural host-parasite interactions is that hosts harbour a community of parasite species that are interconnected through the use of the common host as a resource, interspecific parasite-parasite interactions, and direct and indirect effects of host immunity (e.g., $[110,111])$. Parasite-mediated divergent selection can vary between host populations both in strength of selection imposed by one parasite species, in the number of different parasite species, and in the number of traits or genes affected. In other words, it is essential to understand the relative importance to speciation of shifts in the strength of selection exerted by one parasite or in the number of parasite species together exerting multifarious selection. However, strength and dimensionality of parasite-mediated selection in the context of host divergence and speciation is currently largely unknown. Empirical examples typically report multiple parasite species infections in the diverging host populations, some of which show differences between the populations. Hence, current data tend to suggest that diverging ecotypes are often exposed to divergent parasite species assemblages (Table 1). The role of individual species and especially their joint effects, however, are poorly known.

In sticklebacks, parasite diversity tends at least sometimes to be positively associated with host diversity at MHC loci $[54,112]$ suggesting that multiple parasite species could be driving host population divergence at multiple MHC loci. However, typically some parasite species impose stronger selection, for example, because they are more numerous, have larger body size, or infect a more vital organ of the host. For example in German sticklebacks, resistance against Gyrodactylus parasites is determined by a certain MHC haplotype in river populations, whereas that same haplotype when occurring in the lake population results in slightly higher parasite numbers [54] (Figure 4). Given that MHC-mediated resistance correlates with reproductive success [92], the opposite outcomes of infection in different environments could facilitate speciation [54]. This supports the role of this individual parasite species in divergence of the host populations. However, variable outcomes of selection in different combinations of parasite species are nevertheless likely; one species could drive the selection on its own in some populations favouring the idea of strong selection, while effects from multiple species predominate in other systems supporting multifarious selection. It is also generally unknown if selection imposed by different parasite species takes the same direction with regard to fitness effects of migration and gene flow, and hence speciation. For example, Keller et al. [97] found evidence for stabilizing selection on one and divergent selection of another locus in the MHC gene family in Alpine trouts. On the scale of entire parasite communities, such interactions may be complex and difficult to resolve. However, search for recurring patterns of infections and resistance in replicated pairs of similar ecotypes, or along a speciation continuum, could provide some tools to tackle the relative importance of strong and multifarious selection.

4.3. Measuring Relative Rates of Adaptation in Parasites and Hosts. Measuring relative rates of adaptation in parasites and their hosts could allow empirical testing of the theoretical predictions about when parasite-host coevolution should facilitate and when it should actually constrain speciation in host populations. Theoretical considerations predict that parasite-host coevolution should facilitate speciation in host populations when host populations can adapt to the parasite community that infects them. In this situation, gene flow from nonadapted host populations could be maladaptive, and assortative mating between host populations may evolve by either of the three mechanisms reviewed above. On the other hand, when parasites adapt to their local host population (reviews in [113-115]), gene flow into the host population from outside could be adaptive because it would provide genetic variants not known to the local parasites that escape parasitism. Parasite-host coevolution should constrain speciation in host populations in this scenario [53]. Given that most parasites have faster generation times than their hosts, it seems that the second scenario could apply quite often. Conditions favourable to host speciation would include situations where hosts are ahead of their parasites in the coevolutionary race, for example, because parasite adaptation is genetically constrained. They may also entail situations where host-parasite coevolution happens in oneto-many or many-to-many constellations. In such situations, adapted hosts may cope well with the local community of diverse parasites without coevolving closely with any one of them. Very few existing data speak to these theoretical predictions. One interesting corollary of the above is that the odds of speciation in hosts and those in parasites should often be negatively correlated. Very high speciation rates in parasites compared to their hosts have been described for example in monogenean platyhelminthes infecting freshwater fishes [116]. To the extent that these parasites evolve host-specific adaptations, they might facilitate outbreeding and constrain speciation in host populations.

\section{Reversal of Speciation}

Some of the best examples of adaptive radiation come from freshwater fishes, and in several of these the frequent reversal of speciation has also been described particularly as a consequence of human activity. The most compelling evidence comes from cichlid fishes in Lake Victoria, stickleback in Western Canada, and whitefish and ciscoes in central Europe and North America [117, 118]. Rapid adaptive radiation in Lake Victoria has produced a magnificent diversity of hundreds of cichlid species. One likely mechanism driving speciation involves evolution in the visual system and of visual signals in response to heterogeneous light conditions, and its effects on mate choice and speciation through mechanisms related to sensory drive [10]. However, increasing eutrophication of the lake from the 1920s and subsequent turbidity of the water have resulted in relaxation 
of the diversity-maintaining mate selection and collapse of species diversity in some parts of the lake [119]. Similar collapses of species diversity through loss of reproductive isolation following anthropogenic impacts have occurred in ciscoes of the Laurentian Great lakes, in whitefish of Swiss prealpine lakes [118], and in Canadian sticklebacks [120].

5.1. Role for Parasites? The above observations relate to the hypothesis of parasite-mediated speciation in two ways. First, investigating mechanisms and processes of speciation reversal may also shed light onto those promoting ecological speciation. In general, reversal of speciation may (re)create a speciation continuum, where formerly distinct sympatric species become admixed to variable degrees, with variation in time, space, or both. Capturing and studying such changes as they happen in nature could provide effective tools to evaluate the possible role of parasites in divergence of natural host populations. For example, environmental changes such as pollution and eutrophication may affect not only the host community, but could change biomass and reduce the diversity of parasite species as well, with species having multiple host life cycles probably being among the most prone to extinction $[47,121]$. Changes that relax parasitemediated divergent selection among host populations could lead to gradual loss of reproductive isolation, but also reveal the role of specific parasite species that had maintained the divergence. Additionally, experimental work is also needed to address the possible role of parasites in breaking down speciation or preventing it, something that is known very little about.

Second, it is possible that certain parasite species may directly drive reversal or prevention of speciation. In systems where divergence of species is maintained by divergent adaptation in the visual system, and visually mediated sexual selection, such as African cichlids and sticklebacks, parasites that influence host vision might have effects comparable to loss of visibility due to eutrophication. One group of such parasites are those of the genus Diplostomum that infect eyes of a range of freshwater fish species around the world causing cataracts and partial or total blindness (Figure 1; [122]). Infection has dramatic effects on fish [123-125] and it could also impair the ability of fish to visually select mates. For example, females with impaired visual ability could be less choosy as they cannot properly assess the quality of the male colouration or courtship. Impaired vision of males, on the other hand, could affect their ability to compete with other males, court females or, in case of sticklebacks, build nests. The risk of eye fluke infection is typically variable in both space and time, which can result even in total absence of infection from some lakes (Karvonen et al., unpublished). This could set up very different conditions for host divergence mediated by vision-based mate choice within allopatric host populations. For example, it is tempting to ask if divergence of the hosts under such circumstances would be more likely in populations that are only moderately, or not at all, infected with eye flukes, conceptually linking this to the effect of eutrophication on the loss of diversity of cichlid fishes in Lake Victoria [119]. Comparative experimental approaches could shed light onto these associations and will be needed to link the probability of infection with the degree of host population divergence observed in nature.

Also other infections could lead to alterations in mate choice and sexual selection, possibly resulting in reduced probability of host divergence or in reversal of speciation. For example, several parasite species alter the behaviour or appearance of their hosts as a side effect of infection or by actively manipulating the host to improve transmission $[21,23]$. Depending on the prevalence of such infections in a host population, this could dramatically change sexual selection. For example, it has been suggested that effects of Schistocephalus infection on the growth of sticklebacks directly affect assortative mating which is based at least partly on size [126]. Coinfections with several parasite species that commonly prevail in wild hosts may also change circumstances for sexual selection in hosts. For example, whereas some parasite species use hosts as transmission vehicles to the next host by manipulating their behaviour, other species may use the same host individuals for reproduction and completion of the life cycle. Two parasite species with complex life cycles can also use the same host individual as a vehicle to different definitive host taxa, such as fish and bird. These situations can result in conflicts between the opposing parasite interests (e.g., $[127,128]$ ), when the outcome for host behaviour and sexual selection may depend on which of the parasite species dominates the coinfection situation. The important point emerging from this is that the variety of interrelated mechanisms by which parasitic infections can reduce host fitness (e.g., depletion of energy, changes in appearance or behaviour, increase in susceptibility to predation) can set up very different conditions for sexual selection depending on how common different types of (co)infections are.

5.2. Speciation by Hybridization. Hybridisation between species can also give rise to new species [129-131]. Hybrid speciation is particularly likely when the hybrid population is able to colonize a niche that is not occupied by either parental species and makes it spatially isolated from both the parental species [132, 133]. A scenario that would be relevant in the context of our review is if hybrids are able to colonize a novel niche where infections differ from those in the parental niches. In principle it is then even possible that parasite-mediated reversal of speciation, happening in parts of the larger range of the parental species, could lead to the local emergence of a new hybrid species. There currently is a growing number of empirical examples of hybrid speciation both from plant and animal systems (reviewed in $[131,134]$ ), and it will be interesting to see if future studies will pick up a signature of parasite-mediated selection in some of these cases.

5.3. Parasitism, Phenotypic Plasticity, and Speciation. The above scenarios of infections that influence the condition or behaviour of their host may also be relevant in the context of old and recent discussions on the role of plasticity in generating reproductive isolation that precedes any adaptive divergence (e.g., [135, 136]; Fitzpatrick, this issue [137]). In host-parasite interactions, such plasticity could be observed, 
for example, if reduction or change in host condition or behaviour as a result of infection leads to conditiondependent habitat choice and thus promotes reproductive isolation between individuals (see [138]). Phenotypic variation in individual's ability to avoid infections by shifting to another habitat away from the infection source (e.g., [139]) could also contribute to segregation. Moreover, such behaviours could be further shaped or reinforced by the earlier infection experience and "learning" of an individual $[140,141]$. Overall, there are several ways how plastic responses of hosts to a parasite infection could contribute to reproductive isolation, but they wait for empirical tests.

\section{Conclusions}

Empirical evidence available today has just begun to unravel mechanisms of parasite-mediated selection and how these affect the course of ecological speciation. Evidence for direct natural selection is equivocal because reduced viability or fecundity of immigrants may be compensated by hybrid vigour. Evidence for pleiotropy through effects of MHC on assortative mating is mixed too because divergent and stabilizing selection both occur, sometimes even in the same populations, and because MHC may not be an overriding mate choice cue. Evidence for parasite-mediated divergent sexual selection is scarce and incomplete, with best examples perhaps from Arctic charr and cichlid fish. The future should see more detailed investigations of parasitism and host resistance at all stages of speciation. Importantly, such investigations must become part and parcel of an integrated analytical and experimental research framework on ecological speciation. Particular emphasis should be placed on studying the entire speciation continuum and not just the beginning and end. This is the only way to determine whether, how and at what stage parasites begin to influence a divergence process that actually has ecological speciation as its end product. Further, empirical testing of the theoretical predictions about when parasite-host coevolution should facilitate and when it should constrain speciation in host populations has great potential to make major contributions to an integration of the currently still disparate literature. Clearly expectations should depend on the relative rates of and constrains to evolutionary adaptation in parasites and their hosts, and it is likely that the current lack of data on this explains some of the variable and contradictory results of empirical studies. Finally, many more speciating taxa ought to be studied to identify generalities.

\section{References}

[1] G. G. Simpson, The Major Features of Evolution, Columbia University Press, New York, NY, USA, 1953.

[2] D. Jablonski, "Biotic interactions and macroevolution: extensions and mismatches across scales and levels," Evolution, vol. 62, no. 4, pp. 715-739, 2008.

[3] D. Otte and J. A. Endler, Speciation and Its Consequences, Sinauer Associates, Sunderland, Mass, USA, 1989.

[4] J. A. Coyne and H. A. Orr, Speciation, Sinauer Associates, Sunderland, Mass, USA, 2004.
[5] P. Nosil, L. J. Harmon, and O. Seehausen, "Ecological explanations for (incomplete) speciation," Trends in Ecology and Evolution, vol. 24, no. 3, pp. 145-156, 2009.

[6] D. Schluter, "Evidence for ecological speciation and its alternative," Science, vol. 323, no. 5915, pp. 737-741, 2009.

[7] J. M. Sobel, G. F. Chen, L. R. Watt, and D. W. Schemske, "The biology of speciation," Evolution, vol. 64, no. 2, pp. 295-315, 2010.

[8] M. E. Maan and O. Seehausen, "Ecology, sexual selection and speciation," Ecology Letters, vol. 14, no. 6, pp. 591-602, 2011.

[9] P. F. Colosimo, K. E. Hosemann, S. Balabhadra et al., "Widespread parallel evolution in sticklebacks by repeated fixation of ectodysplasin alleles," Science, vol. 307, no. 5717, pp. 1928-1933, 2005.

[10] O. Seehausen, Y. Terai, I. S. Magalhaes et al., "Speciation through sensory drive in cichlid fish," Nature, vol. 455, no. 7213, pp. 620-627, 2008.

[11] D. Schluter and G. L. Conte, "Genetics and ecological speciation," Proceedings of the National Academy of Sciences of the United States of America, vol. 106, pp. 9955-9962, 2009.

[12] C. Salazar, S. W. Baxter, C. Pardo-Diaz et al., "Genetic evidence for hybrid trait speciation in Heliconius butterflies," PLoS Genetics, vol. 6, no. 4, article e1000930, 2010.

[13] P. Nosil and D. Schluter, "The genes underlying the process of speciation," Trends in Ecology and Evolution, vol. 26, no. 4, pp. 160-167, 2011.

[14] D. Schluter, The Ecology of Adaptive Radiation, Oxford University Press, 2000.

[15] H. D. Rundle and P. Nosil, "Ecological speciation," Ecology Letters, vol. 8, no. 3, pp. 336-352, 2005.

[16] T. E. Reimchen, "Living in the ecological theatre," in Tinbergen's Legacy in Behaviour. Sixty Years of Landmark Stickleback Papers, F. A. von Hippel, Ed., pp. 385-392, Brill, The Netherlands, 2010.

[17] S. M. Vamosi, "The presence of other fish species affects speciation in threespine sticklebacks," Evolutionary Ecology Research, vol. 5, no. 5, pp. 717-730, 2003.

[18] P. Nosil and B. J. Crespi, "Experimental evidence that predation promotes divergence in adaptive radiation," Proceedings of the National Academy of Sciences of the United States of America, vol. 103, no. 24, pp. 9090-9095, 2006.

[19] R. Poulin, "How many parasite species are there: are we close to answers?" International Journal for Parasitology, vol. 26, no. 10, pp. 1127-1129, 1996.

[20] D. A. Windsor, "Most of the species on Earth are parasites," International Journal for Parasitology, vol. 28, no. 12, pp. 1939-1941, 1998.

[21] R. Poulin, “'Adaptive' changes in the behaviour of parasitized animals: a critical review," International Journal for Parasitology, vol. 25, no. 12, pp. 1371-1383, 1995.

[22] P. J. Hudson, A. P. Dobson, and D. Newborn, "Prevention of population cycles by parasite removal," Science, vol. 282, no. 5397, pp. 2256-2258, 1998.

[23] J. Moore, Parasites and the Behaviour of Animals, Oxford University Press, 2002.

[24] J. Jokela, M. F. Dybdahl, and C. M. Lively, "The maintenance of sex, clonal dynamics, and host-parasite coevolution in a mixed population of sexual and asexual snails," American Naturalist, vol. 174, no. 1, pp. S43-S53, 2009.

[25] J. B. S. Haldane, “Disease and evolution,” La Ricerca Scientifica, vol. 19, pp. 68-76, 1949.

[26] P. W. Price, M. Westoby, B. Rice et al., "Parasite mediation in ecological interactions," Annual Review of Ecology and Systematics, vol. 17, pp. 487-505, 1986. 
[27] W. J. Freeland, "Parasites and the coexistence of animal host species," American Naturalist, vol. 121, no. 2, pp. 223-236, 1983.

[28] M. D. Pagel, R. M. May, and A. R. Collie, "Ecological aspects of the geographical distribution and diversity of mammalian species," American Naturalist, vol. 137, no. 6, pp. 791-815, 1991.

[29] B. R. Krasnov, G. I. Shenbrot, I. S. Khokhlova, and A. A. Degen, "Relationship between host diversity and parasite diversity: flea assemblages on small mammals," Journal of Biogeography, vol. 31, no. 11, pp. 1857-1866, 2004.

[30] C. L. Nunn, S. Altizer, W. Sechrest, K. E. Jones, R. A. Barton, and J. L. Gittleman, "Parasites and the evolutionary diversification of primate clades," American Naturalist, vol. 164, no. 5, pp. S90-S103, 2004.

[31] C. L. Fincher and R. Thornhill, "A parasite-driven wedge: infectious diseases may explain language and other biodiversity," Oikos, vol. 117, no. 9, pp. 1289-1297, 2008.

[32] J. B. Yoder and S. L. Nuismer, "When does coevolution promote diversification?" American Naturalist, vol. 176, no. 6, pp. 802-817, 2010.

[33] P. R. Ehrlich and P. H. Raven, "Butterflies and plants—a study in coevolution," Evolution, vol. 18, pp. 586-608, 1964.

[34] M. Bueno-Silva, W. A. Boeger, and M. R. Pie, "Choice matters: incipient speciation in Gyrodactylus corydori (Monogenoidea: Gyrodactylidae)," International Journal for Parasitology, vol. 41, no. 6, pp. 657-667, 2011.

[35] N. Nishimura, D. C. Heins, R. O. Andersen, I. Barber, and W. A. Cresko, "Distinct lineages of Schistocephalus parasites in threespine and ninespine stickleback hosts revealed by DNA sequence analysis," PLoS One, vol. 6, no. 7, article e22505, 2011.

[36] I. Emelianov, A. Hernandes-Lopez, M. Torrence, and N. Watts, "Fusion-fission experiments in Aphidius: evolutionary split without isolation in response to environmental bimodality," Heredity, vol. 106, pp. 798-807, 2010.

[37] R. Knudsen, P. A. Amundsen, and A. Klemetsen, "Arctic charr in sympatry with burbot: ecological and evolutionary consequences," Hydrobiologia, vol. 650, no. 1, pp. 43-54, 2010.

[38] R. Knudsen, R. Primicerio, P. A. Amundsen, and A. Klemetsen, "Temporal stability of individual feeding specialization may promote speciation," Journal of Animal Ecology, vol. 79, no. 1, pp. 161-168, 2010.

[39] R. Knudsen, A. Siwertsson, C. E. Adams, M. Garduño-Paz, J. Newton, and P. A. Amundsen, "Temporal stability of niche use exposes sympatric Arctic charr to alternative selection pressures," Evolutionary Ecology, vol. 25, pp. 589-604, 2010.

[40] B. A. Fraser and B. D. Neff, "Parasite mediated homogenizing selection at the MHC in guppies," Genetica, vol. 138, no. 2, pp. 273-278, 2010.

[41] R. E. Ricklefs, "Host-pathogen coevolution, secondary sympatry and species diversification," Philosophical Transactions of the Royal Society B, vol. 365, no. 1543, pp. 1139-1147, 2010.

[42] M. D. Sorenson and R. B. Payne, "A single ancient origin of brood parasitism in African finches: implications for hostparasite coevolution," Evolution, vol. 55, no. 12, pp. 25502567, 2001.

[43] G. Sharon, D. Segal, J. M. Ringo, A. Hefetz, I. ZilberRosenberg, and E. Rosenberg, "Commensal bacteria play a role in mating preference of Drosophila melanogaster,"
Proceedings of the National Academy of Sciences of the United States of America, vol. 107, no. 46, pp. 20051-20056, 2010.

[44] A. Buckling and P. B. Rainey, "The role of parasites in sympatric and allopatric host diversification," Nature, vol. 420, no. 6915, pp. 496-499, 2002.

[45] M. A. Brockhurst, P. B. Rainey, and A. Buckling, "The effect of spatial heterogeneity and parasites on the evolution of host diversity," Proceedings of the Royal Society B, vol. 271, no. 1534, pp. 107-111, 2004.

[46] G. W. Esch, A. O. Bush, and J. M. Aho, Eds., Parasite Communities: Patterns and Processes, Chapman and Hall, London, UK, 1990.

[47] E. T. Valtonen, J. C. Holmes, and M. Koskivaara, "Eutrophication, pollution, and fragmentation: effects on parasite communities in roach (Rutilus rutilus) and perch (Perca fluviatilis) in four lakes in central Finland," Canadian Journal of Fisheries and Aquatic Sciences, vol. 54, no. 3, pp. 572-585, 1997.

[48] R. Poulin, Evolutionary Ecology of Parasites, Princeton University Press, NJ, USA, 2007.

[49] R. Poulin, "The decay of similarity with geographical distance in parasite communities of vertebrate hosts," Journal of Biogeography, vol. 30, no. 10, pp. 1609-1615, 2003.

[50] J. Soininen, R. McDonald, and H. Hillebrand, "The distance decay of similarity in ecological communities," Ecography, vol. 30, no. 1, pp. 3-12, 2007.

[51] A. Karvonen, G. H. Cheng, and E. T. Valtonen, "Within-lake dynamics in the similarity of parasite assemblages of perch (Perca fluviatilis)," Parasitology, vol. 131, no. 6, pp. 817-823, 2005.

[52] C. Eizaguirre and T. L. Lenz, "Major histocompatability complex polymorphism: dynamics and consequences of parasite-mediated local adaptation in fishes," Journal of Fish Biology, vol. 77, no. 9, pp. 2023-2047, 2010.

[53] K. Summers, S. McKeon, J. Sellars et al., "Parasitic exploitation as an engine of diversity," Biological Reviews of the Cambridge Philosophical Society, vol. 78, no. 4, pp. 639-675, 2003.

[54] C. Eizaguirre, T. L. Lenz, R. D. Sommerfeld, C. Harrod, M. Kalbe, and M. Milinski, "Parasite diversity, patterns of MHC II variation and olfactory based mate choice in diverging three-spined stickleback ecotypes," Evolutionary Ecology, vol. 25, pp. 605-622, 2010.

[55] G. Rauch, M. Kalbe, and T. B. H. Reusch, "Relative importance of MHC and genetic background for parasite load in a field experiment," Evolutionary Ecology Research, vol. 8, no. 2, pp. 373-386, 2006.

[56] J. P. Scharsack, M. Kalbe, C. Harrod, and G. Rauch, "Habitatspecific adaptation of immune responses of stickleback (Gastetosteus aculeatus) lake and river ecotypes," Proceedings of the Royal Society B, vol. 274, no. 1617, pp. 1523-1532, 2007.

[57] R. J.S. McCairns, S. Bourget, and L. Bernatchez, "Putative causes and consequences of MHC variation within and between locally adapted stickleback demes," Molecular Ecology, vol. 20, no. 3, pp. 486-502, 2011.

[58] A. D. C. MacColl, "Parasite burdens differ between sympatric three-spined stickleback species," Ecography, vol. 32, no. 1, pp. 153-160, 2009.

[59] R. Knudsen, R. Kristoffersen, and P. A. Amundsen, "Parasite communities in two sympatric morphs of Arctic charr, Salvelinus alpinus (L.), in northern Norway," Canadian Journal of Zoology, vol. 75, no. 12, pp. 2003-2009, 1997. 
[60] R. Knudsen, P. A. Amundsen, and A. Klemetsen, "Inter- and intra-morph patterns in helminth communities of sympatric whitefish morphs," Journal of Fish Biology, vol. 62, no. 4, pp. 847-859, 2003.

[61] F. Frandsen, H. J. Malmquist, and S. S. Snorrason, "Ecological parasitology of polymorphic Arctic charr, Salvelinus alpinus (L.), in Thingvallavatn, Iceland," Journal of Fish Biology, vol. 34, no. 2, pp. 281-297, 1989.

[62] A. Karvonen, B. Lundsgaard-Hansen, J. Jokela, and O. Seehausen, "Differentiation in parasitism among ecotypes of whitefish segregating along depth gradients," Oikos. In press.

[63] T. D. Kocher, "Adaptive evolution and explosive speciation: the cichlid fish model," Nature Reviews Genetics, vol. 5, no. 4, pp. 288-298, 2004.

[64] M. J. Genner and G. F. Turner, "The mbuna cichlids of Lake Malawi: a model for rapid speciation and adaptive radiation," Fish and Fisheries, vol. 6, no. 1, pp. 1-34, 2005.

[65] O. Seehausen, "African cichlid fish: a model system in adaptive radiation research," Proceedings of the Royal Society B, vol. 273, no. 1597, pp. 1987-1998, 2006.

[66] M. E. Maan, A. M. C. Van Rooijen, J. J. M. Van Alphen, and O. Seehausen, "Parasite-mediated sexual selection and species divergence in Lake Victoria cichlid fish," Biological Journal of the Linnean Society, vol. 94, no. 1, pp. 53-60, 2008.

[67] J. Blais, C. Rico, C. van Oosterhout, J. Cable, G. F. Turner, and L. Bernatchez, "MHC adaptive divergence between closely related and sympatric African cichlids," PLoS One, vol. 2, no. 8, article no. e734, 2007.

[68] P. Nosil, T. H. Vines, and D. J. Funk, "Perspective: reproductive isolation caused by natural selection against immigrants from divergent habitats," Evolution, vol. 59, no. 4, pp. 705719, 2005.

[69] M. Milinski, "The major histocompatibility complex, sexual selection, and mate choice," Annual Review of Ecology, Evolution, and Systematics, vol. 37, pp. 159-186, 2006.

[70] A. D.C. MacColl and S. M. Chapman, "Parasites can cause selection against migrants following dispersal between environments," Functional Ecology, vol. 24, no. 4, pp. 847856, 2010.

[71] E. A. MacDougall-Shackleton, E. P. Derryberry, and T. Hahn, "Nonlocal male mountain white-crowned sparrows have lower paternity and higher parasite loads than males signing local dialect," Behavioural Ecology, vol. 13, pp. 682-689, 2002.

[72] R. S. Fritz, C. Moulia, and G. Newcombe, "Resistance of hybrid plants and animals to herbivores, pathogens, and parasites," Annual Review of Ecology and Systematics, vol. 30, pp. 565-591, 1999.

[73] C. Moulia, "Parasitism of plant and animal hybrids: are facts and fates the same?" Ecology, vol. 80, no. 2, pp. 392-406, 1999.

[74] C. Wiley, A. Qvarnström, and L. Gustafsson, "Effects of hybridization on the immunity of collared ficedula albicollis and pied flycatchers $\mathrm{f}$. hypoleuca, and their infection by haemosporidians," Journal of Avian Biology, vol. 40, no. 4, pp. 352-357, 2009.

[75] E. A. MacDougall-Shackleton, E. P. Derryberry, J. Foufopoulos, A. P. Dobson, and T. P. Hahn, "Parasite-mediated heterozygote advantage in an outbred songbird population," Biology Letters, vol. 1, no. 1, pp. 105-107, 2005.

[76] M. A. Patten, J. T. Rotenberry, and M. Zuk, "Habitat selection, acoustic adaptation, and the evolution of reproductive isolation," Evolution, vol. 58, no. 10, pp. 2144-2155, 2004.
[77] A. B. Marr, L. F. Keller, and P. Arcese, "Heterosis and outbreeding depression in descendants of natural immigrants to an inbred population of song sparrows (Melospiza melodia)," Evolution, vol. 56, no. 1, pp. 131-142, 2002.

[78] J. Wolinska, B. Keller, K. Bittner, S. Lass, and P. Spaak, "Do parasites lower Daphnia hybrid fitness?" Limnology and Oceanography, vol. 49, no. 4, pp. 1401-1407, 2004.

[79] S. L. Nuismer and S. Gandon, "Moving beyond commongarden and transplant designs: insight into the causes of local adaptation in species interactions," American Naturalist, vol. 171, no. 5, pp. 658-668, 2008.

[80] S. Gandon and S. L. Nuismer, "Interactions between genetic drift, gene flow, and selection mosaics drive parasite local adaptation," American Naturalist, vol. 173, no. 2, pp. 212224, 2009.

[81] O. Seppälä, A. Karvonen, E. T. Valtonen, and J. Jokela, “Interactions among co-infecting parasite species: a mechanism maintaining genetic variation in parasites?" Proceedings of the Royal Society B, vol. 276, no. 1657, pp. 691-697, 2009.

[82] O. Seppälä, A. Karvonen, M. Haataja, M. Kuosa, and J. Jokela, "Food makes you a target: disentangling genetic, physiological, and behavioral effects determining susceptibility to infection," Evolution, vol. 65, no. 5, pp. 1367-1375, 2011.

[83] S. L. Nuismer, S. P. Otto, and F. Blanquart, "When do host-parasite interactions drive the evolution of non-random mating?” Ecology Letters, vol. 11, no. 9, pp. 937-946, 2008.

[84] G. Valkiunas, D. Santiago-Alarcon, I. I. Levin, T. A. Iezhova, and P. G. Parker, "A new Haemoproteus species (Haemosporida: Haemoproteidae) from the endemic galapagos dove Zenaida galapagoensis, with remarks on the parasite distribution, vectors, and molecular diagnostics," Journal of Parasitology, vol. 96, no. 4, pp. 783-792, 2010.

[85] C. Landry, D. Garant, P. Duchesne, and L. Bernatchez, "'Good genes as heterozygosity': the major histocompatibility complex and mate choice in Atlantic salmon (Salmo salar)," Proceedings of the Royal Society B, vol. 268, no. 1473, pp. 1279-1285, 2001.

[86] L. Bernatchez and C. Landry, "MHC studies in nonmodel vertebrates: what have we learned about natural selection in 15 years?" Journal of Evolutionary Biology, vol. 16, no. 3, pp. 363-377, 2003.

[87] B. Woelfing, A. Traulsen, M. Milinski, and T. Boehm, "Does intra-individual major histocompatibility complex diversity keep a golden mean?" Philosophical Transactions of the Royal Society B, vol. 364, no. 1513, pp. 117-128, 2009.

[88] M. Milinski, S. Griffiths, K. M. Wegner, T. B. H. Reusch, A. Haas-Assenbaum, and T. Boehm, "Mate choice decisions of stickleback females predictably modified by MHC peptide ligands," Proceedings of the National Academy of Sciences of the United States of America, vol. 102, no. 12, pp. 4414-4418, 2005.

[89] C. Eizaguirre, T. L. Lenz, A. Traulsen, and M. Milinski, "Speciation accelerated and stabilized by pleiotropic major histocompatibility complex immunogenes," Ecology Letters, vol. 12, no. 1, pp. 5-12, 2009.

[90] M. Kalbe, K. M. Wegner, and T. B. H. Reusch, "Dispersion patterns of parasites in $0+$ year three-spined sticklebacks: a cross population comparison," Journal of Fish Biology, vol. 60, no. 6, pp. 1529-1542, 2002.

[91] B. Matthews, L. J. Harmon, L. M’Gonigle, K. B. Marchinko, and H. Schaschl, "Sympatric and allopatric divergence of MHC genes in threespine stickleback," PLoS One, vol. 5, no. 6, Article ID e10948, 2010. 
[92] C. Eizaguirre, S. E. Yeates, T. L. Lenz, M. Kalbe, and M. Milinski, "MHC-based mate choice combines good genes and maintenance of MHC polymorphism," Molecular Ecology, vol. 18, no. 15, pp. 3316-3329, 2009.

[93] J. A. M. Raeymaekers, M. Boisjoly, L. Delaire, D. Berner, K. Räsänen, and A. P. Hendry, "Testing for mating isolation between ecotypes: laboratory experiments with lake, stream and hybrid stickleback," Journal of Evolutionary Biology, vol. 23, no. 12, pp. 2694-2708, 2010.

[94] K. Räsänen, M. Delcourt, L. J. Chapman, and A. P. Hendry, "Divergent selection and then not: the puzzle of reproductive isolationin Misty lake and stream stickleback," International Journal of Ecology. In press.

[95] K. M. Wegner, M. Kalbe, J. Kurtz, T. B. H. Reusch, and M. Milinski, "Parasite selection for immunogenetic optimality," Science, vol. 301, no. 5638, p. 1343, 2003.

[96] J. Kurtz, M. Kalbe, P. B. Aeschlimann et al., "Major histocompatibility complex diversity influences parasite resistance and innate immunity in sticklebacks," Proceedings of the Royal Society B, vol. 271, no. 1535, pp. 197-204, 2004.

[97] I. Keller, A. Taverna, and O. Seehausen, "Evidence of neutral and adaptive genetic divergence between European trout populations sampled along altitudinal gradients," Molecular Ecology, vol. 20, no. 9, pp. 1888-1904, 2011.

[98] M. G. Ritchie, "Sexual selection and speciation," Annual Review of Ecology, Evolution, and Systematics, vol. 38, pp. 79102, 2007.

[99] W. D. Hamilton and M. Zuk, "Heritable true fitness and bright birds-a role for parasites?" Science, vol. 218, no. 4570, pp. 384-387, 1982.

[100] F. Skarstein, I. Folstad, and H. P. Rønning, "Spawning colouration, parasites and habitat selection in Salvelinus alpinus: initiating speciation by sexual selection?" Journal of Fish Biology, vol. 67, no. 4, pp. 969-980, 2005.

[101] M. E. Maan, M. Van Der Spoel, P. Q. Jimenez, J. J. M. Van Alphen, and O. Seehausen, "Fitness correlates of male coloration in a Lake Victoria cichlid fish," Behavioral Ecology, vol. 17, no. 5, pp. 691-699, 2006.

[102] O. Seehausen and J. J. M. Van Alphen, "The effect of male coloration on female mate choice in closely related Lake Victoria cichlids (Haplochromis nyererei complex)," Behavioral Ecology and Sociobiology, vol. 42, no. 1, pp. 1-8, 1998.

[103] M. E. Maan, O. Seehausen, L. Söderberg et al., "Intraspecific sexual selection on a speciation trait, male coloration, in the Lake Victoria cichlid Pundamilia nyererei," Proceedings of the Royal Society B, vol. 271, no. 1556, pp. 2445-2452, 2004.

[104] O. Seehausen, "Progressive levels of trait divergence along a 'speciation transect' in the Lake Victoria cichlid fish Pundamilia," in Ecological Reviews: Speciation and Patterns of Diversity, R. Butlin, J. Bridle, and D. Schluter, Eds., pp. 155176, Cambridge University Press, 2009.

[105] A. P. Hendry, D. I. Bolnick, D. Berner, and C. L. Peichel, "Along the speciation continuum in sticklebacks," Journal of Fish Biology, vol. 75, no. 8, pp. 2000-2036, 2009.

[106] D. Schluter and L. M. Nagel, "Parallel speciation by natural selection," American Naturalist, vol. 146, no. 2, pp. 292-301, 1995.

[107] H. D. Rundle, L. Nagel, J. W. Boughman, and D. Schluter, "Natural selection and parallel speciation in sympatric sticklebacks," Science, vol. 287, no. 5451, pp. 306-308, 2000.
[108] K. L. Ostevik, B. T. Moyers, G. L. Owens, and L. H. Rieseberg, "Parallel ecological speciation in plants?" International Journal of Ecology, vol. 2012, Article ID 939862, 2012.

[109] B. A. Fraser, I. W. Ramnarine, and B. D. Neff, "Temporal variation at the MHC class IIb in wild populations of the guppy (Poecilia reticulata)," Evolution, vol. 64, no. 7, pp. 2086-2096, 2010.

[110] R. Poulin, "Interactions between species and the structure of helminth communities," Parasitology, vol. 122, pp. S3-S11, 2001.

[111] A. Karvonen, O. Seppälä, and E. Tellervo Valtonen, "Host immunization shapes interspecific associations in trematode parasites," Journal of Animal Ecology, vol. 78, no. 5, pp. 945952, 2009.

[112] K. M. Wegner, T. B. H. Reusch, and M. Kalbe, "Multiple parasites are driving major histocompatibility complex polymorphism in the wild," Journal of Evolutionary Biology, vol. 16, no. 2, pp. 224-232, 2003.

[113] O. Kaltz and J. A. Shykoff, "Local adaptation in host-parasite systems," Heredity, vol. 81, no. 4, pp. 361-370, 1998.

[114] T. J. Kawecki and D. Ebert, "Conceptual issues in local adaptation," Ecology Letters, vol. 7, no. 12, pp. 1225-1241, 2004.

[115] M. A. Greischar and B. Koskella, "A synthesis of experimental work on parasite local adaptation," Ecology Letters, vol. 10, no. 5, pp. 418-434, 2007.

[116] M. S. Zietara and J. Lumme, "Speciation by host switch and adaptive radiation in a fish parasite genus Gyrodactylus (Monogenea, Gyrodactylidae)," Evolution, vol. 56, no. 12, pp. 2445-2458, 2002.

[117] O. Seehausen, "Conservation: losing biodiversity by reverse speciation," Current Biology, vol. 16, no. 9, pp. R334-R337, 2006.

[118] P. Vonlanthen, D. Bittner, A. G. Hudson et al., "Eutrophication causes speciation reversal in whitefish adaptive radiations," Nature, vol. 482, no. 7385, pp. 357-362, 2012.

[119] O. Seehausen, J. J. M. Van Alphen, and F. Witte, "Cichlid fish diversity threatened by eutrophication that curbs sexual selection," Science, vol. 277, no. 5333, pp. 1808-1811, 1997.

[120] E. B. Taylor, J. W. Boughman, M. Groenenboom, M. Sniatynski, D. Schluter, and J. L. Gow, "Speciation in reverse: morphological and genetic evidence of the collapse of a three-spined stickleback (Gasterosteus aculeatus) species pair," Molecular Ecology, vol. 15, no. 2, pp. 343-355, 2006.

[121] D. J. Marcogliese, "Implications of climate change for parasitism of animals in the aquatic environment," Canadian Journal of Zoology, vol. 79, no. 8, pp. 1331-1352, 2001.

[122] A. Karvonen, O. Seppälä, and E. T. Valtonen, "Eye flukeinduced cataract formation in fish: quantitative analysis using an ophthalmological microscope," Parasitology, vol. 129, no. 4, pp. 473-478, 2004.

[123] A. E. Crowden and D. M. Broom, "Effects of the eyefluke, Diplostomum spathaceum, on the behaviour of dace (Leuciscus leuciscus)," Animal Behaviour, vol. 28, no. 1, pp. 287-294, 1980.

[124] O. Seppälä, A. Karvonen, and E. T. Valtonen, "Manipulation of fish host by eye flukes in relation to cataract formation and parasite infectivity," Animal Behaviour, vol. 70, no. 4, pp. 889-894, 2005.

[125] A. Karvonen and O. Seppälä, "Effect of eye fluke infection on the growth of whitefish (Coregonus lavaretus) —an experimental approach," Aquaculture, vol. 279, no. 1-4, pp. 6-10, 2008. 
[126] A. D. C. MacColl, "Parasites may contribute to 'magic trait' evolution in the adaptive radiation of three-spined sticklebacks, Gasterosteus aculeatus (Gasterosteiformes: Gasterosteidae)," Biological Journal of the Linnean Society, vol. 96, no. 2, pp. 425-433, 2009.

[127] S. P. Brown, "Cooperation and conflict in host-manipulating parasites," Proceedings of the Royal Society B, vol. 266, no. 1431, pp. 1899-1904, 1999.

[128] F. Cezilly, A. Gregoire, and A. Bertin, "Conflict between cooccurring manipulative parasites? An experimental study of the joint influence of two acanthocephalan parasites on the behaviour of Gammarus pulex," Parasitology, vol. 120, no. 6, pp. 625-630, 2000.

[129] M. L. Arnold, Natural Hybridization and Evolution, Oxford University Press, USA, 1997.

[130] O. Seehausen, "Hybridization and adaptive radiation," Trends in Ecology and Evolution, vol. 19, no. 4, pp. 198-207, 2004.

[131] J. Mallet, “Hybrid speciation,” Nature, vol. 446, no. 7133, pp. 279-283, 2007.

[132] C. A. Buerkle, R. J. Morris, M. A. Asmussen, and L. H. Rieseberg, "The likelihood of homoploid hybrid speciation," Heredity, vol. 84, no. 4, pp. 441-451, 2000.

[133] C. A. Buerkle, D. E. Wolf, and L. H. Rieseberg, "The origin and extinction of species through hybridization," in Population Viability in Plants: Conservation, Management, and Modeling of Rare Plants, C. A. Brigham and M. W. Schwartz, Eds., pp. 117-141, Springer, Heidelberg, Germany, 2003.

[134] O. Seehausen, G. Takimoto, D. Roy, and J. Jokela, "Speciation reversal and biodiversity dynamics with hybridization in changing environments," Molecular Ecology, vol. 17, no. 1, pp. 30-44, 2008.

[135] D. W. Pfennig, M. A. Wund, E. C. Snell-Rood, T. Cruickshank, C. D. Schlichting, and A. P. Moczek, "Phenotypic plasticity's impacts on diversification and speciation," Trends in Ecology and Evolution, vol. 25, no. 8, pp. 459-467, 2010.

[136] X. Thibert-Plante and A. P. Hendry, "The consequences of phenotypic plasticity for ecological speciation," Journal of Evolutionary Biology, vol. 24, no. 2, pp. 326-342, 2011.

[137] B. M. Fitzpatrick, "Underappreciated consequences of phenotypic plasticity for ecological speciation," International Journal of Ecology, vol. 2012, Article ID 256017, 2012.

[138] P. Edelaar, A. M. Siepielski, and J. Clobert, "Matching habitat choice causes directed gene flow: a neglected dimension in evolution and ecology," Evolution, vol. 62, no. 10, pp. 2462 2472, 2008.

[139] A. Karvonen, O. Seppälä, and E. T. Valtonen, "Parasite resistance and avoidance behaviour in preventing eye fluke infections in fish," Parasitology, vol. 129, no. 2, pp. 159-164, 2004.

[140] C. T. James, K. J. Noyes, A. D. Stumbo, B. D. Wisenden, and C. P. Goater, "Cost of exposure to trematode cercariae and learned recognition and avoidance of parasitism risk by fathead minnows Pimephales promelas," Journal of Fish Biology, vol. 73, no. 9, pp. 2238-2248, 2008.

[141] M. R. Servedio, S. A. Sæther, and G. P. Sætre, "Reinforcement and learning," Evolutionary Ecology, vol. 23, no. 1, pp. 109$123,2009$.

[142] E. B. Taylor and J. D. McPhail, "Historical contingency and ecological determinism interact to prime speciation in sticklebacks, Gasterosteus," Proceedings of the Royal Society B, vol. 267, no. 1460, pp. 2375-2384, 2000.
[143] M. Plenderleith, C. Van Oosterhout, R. L. Robinson, and G. F. Turner, "Female preference for conspecific males based on olfactory cues in a Lake Malawi cichlid fish," Biology Letters, vol. 1, no. 4, pp. 411-414, 2005.

[144] C. J. Allender, O. Seehausen, M. E. Knight, G. F. Turner, and N. Maclean, "Divergent selection during speciation of Lake Malawi cichlid fishes inferred from parallel radiations in nuptial coloration," Proceedings of the National Academy of Sciences of the United States of America, vol. 100, no. 2, pp. 14074-14079, 2003.

[145] A. G. Hudson, P. Vonlanthen, and O. Seehausen, "Rapid parallel adaptive radiations from a single hybridogenic ancestral population," Proceedings of the Royal Society B, vol. 278, no. 1702, pp. 58-66, 2011. 

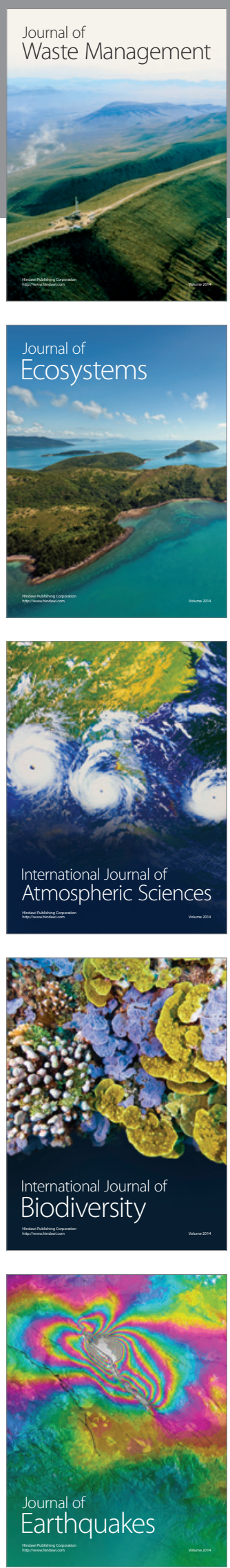
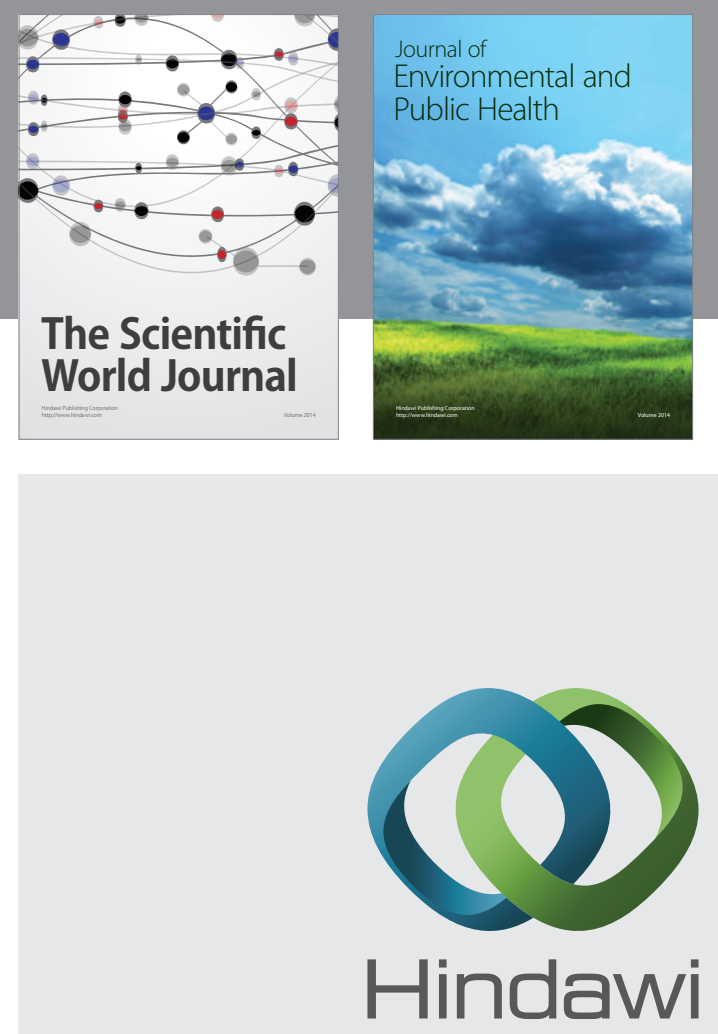

Submit your manuscripts at

http://www.hindawi.com
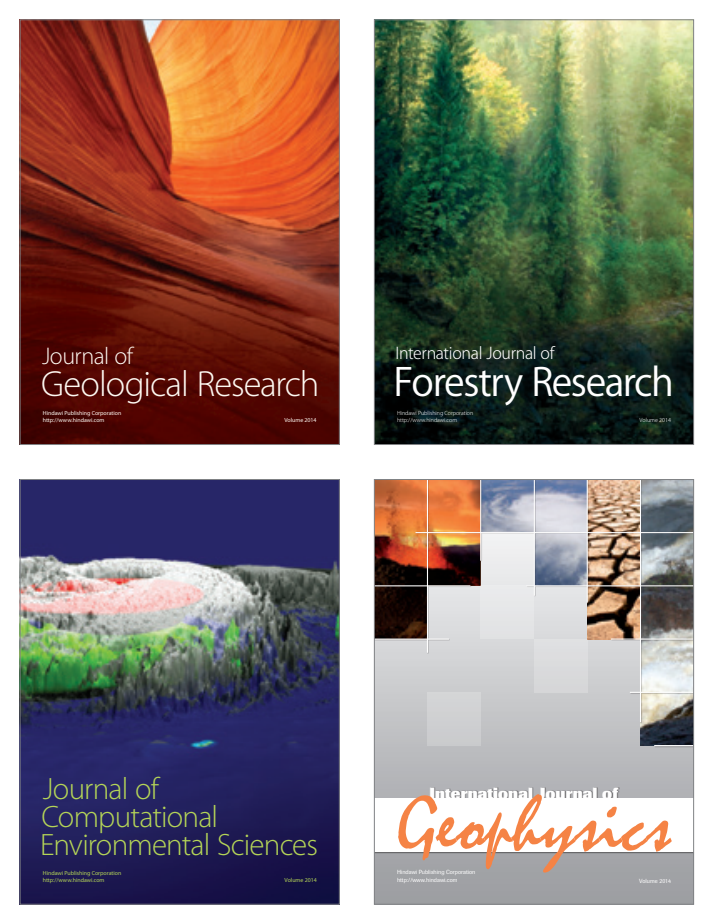
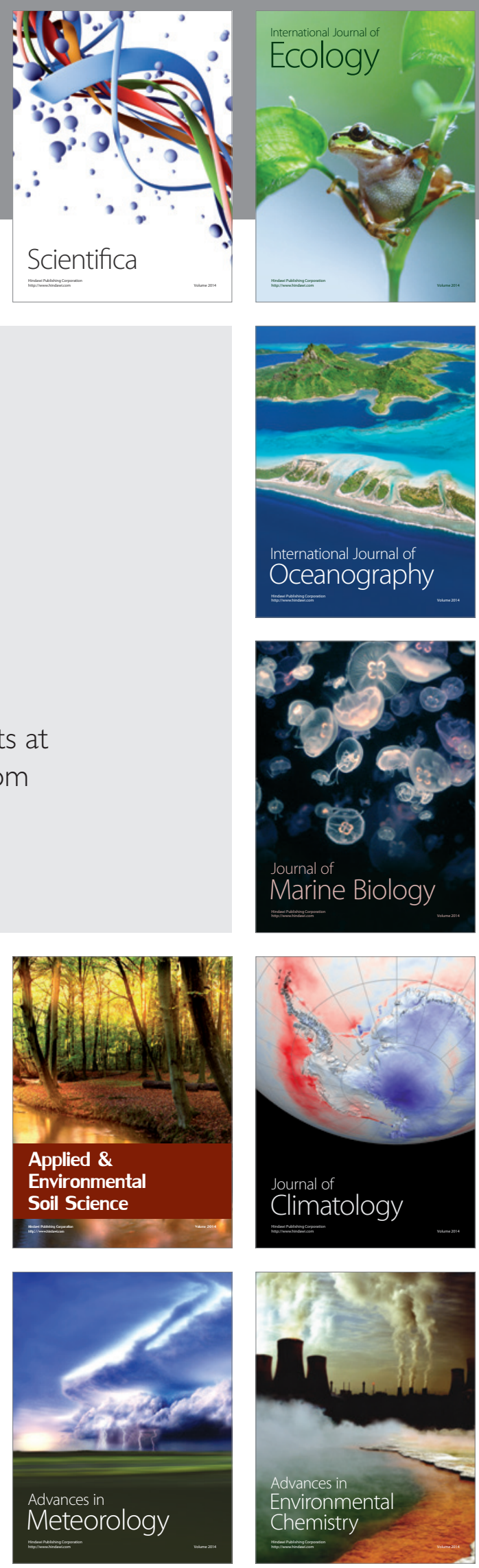